Utah State University

DigitalCommons@USU

$12-2010$

\title{
Mother-Child Attachment and Preschool Behavior Problems in Children with Developmental Delays
}

\author{
Mary S. LaMont \\ Utah State University
}

Follow this and additional works at: https://digitalcommons.usu.edu/etd

Part of the Developmental Psychology Commons, Pre-Elementary, Early Childhood, Kindergarten Teacher Education Commons, and the Special Education and Teaching Commons

\section{Recommended Citation}

LaMont, Mary S., "Mother-Child Attachment and Preschool Behavior Problems in Children with Developmental Delays" (2010). All Graduate Theses and Dissertations. 846.

https://digitalcommons.usu.edu/etd/846

This Dissertation is brought to you for free and open access by the Graduate Studies at DigitalCommons@USU. It has been accepted for inclusion in All Graduate Theses and Dissertations by an authorized administrator of DigitalCommons@USU. For more information, please contact digitalcommons@usu.edu.

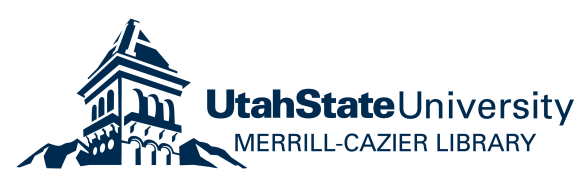




\section{MOTHER-CHILD ATTACHMENT AND PRESCHOOL BEHAVIOR \\ PROBLEMS IN CHILDREN WITH DEVELOPMENTAL DELAYS}

by

Mary LaMont

A dissertation submitted in partial fulfillment

of the requirements for the degree

DOCTOR OF EDUCATION

in

Psychology

Approved:

Gretchen Peacock, Ph.D.

Major Professor

Clint Field, Ph.D.

Committee Member

Donna Gilbertson, Ph.D.

Committee Member
Lisa Boyce, Ph.D.

Committee Member

Mark Innocenti, Ph.D.

Committee Member

Bryon Burnham, Ed.D.

Dean of Graduate Studies

UTAH STATE UNIVERSITY

Logan, Utah 
Copyright (C) Mary Lamont 2010

All Rights Reserved 


\author{
ABSTRACT \\ Mother-Child Attachment and Preschool Behavior Problems \\ in Children with Developmental Delays \\ by \\ Mary LaMont, Doctor of Education \\ Utah State University, 2010
}

Major Professor: Dr. Gretchen Peacock

Department: Psychology

Secure mother-child attachment has been found to be an important factor in the healthy emotional development of children and has been shown to have effects on child, adolescent, and adult behavior. Previous research has primarily focused on attachment in children who are typically developing. However, little research has been conducted in populations of children with developmental delays. The research thus far has suggested that medical situations, child disabilities and maternal emotions may affect interaction patterns between the mother and the child which may in turn influence the security of the mother-child attachment in children with developmental delays. This study contributes to the literature now available. Seventy-four mothers of 11/2- to 2-year-old children in an early intervention program completed a series of questionnaires. Two previously developed pencil-paper measures of attachment behaviors were selected for use in the study due to ease of administration and replication and the need for generalization of 
measures for use in early intervention programs. The Child Attachment Questionnaire (CAQ) and the Attachment Q-Sort Questionnaire (AQSQ) were completed along with measures of parent stress (Parent Stress Index; PSI), maternal psychological problems (Outcomes Questionnaire-45; OQ), socially desirable responses (Marlowe-Crowne Social Desirability Scale; MC), child temperament (Dimensions of Temperament-Revised; DOTS-R), child behavior problems (Child Behavior Checklist-11/2-5; CBCL), and a demographic questionnaire. Compared to numbers published in the literature for typically developing children, the CAQ indicated similar percentages of children with developmental delays fell into secure and insecure categories of attachment while the AQSQ indicated a slightly lower degree of secure attachment for this sample. While parenting stress did predict lower attachment security in this study, social desirable responses were not significantly related to attachment. Maternal psychological problems weakly predicted a higher degree of security. For child factors, gender was not related to attachment and a higher degree of difficulty of temperament predicted lower attachment security. Both paper-pencil measures of attachment were statistically found to be stable over one year's time. As hypothesized, secure attachment was inversely related to behavior problems one year later. Conclusions and clinical implications of these findings are provided and may assist psychologists and early intervention programs in identifying attachment problems and treating with children with developmental delays. 


\section{DEDICATION}

I dedicate this manuscript to my children and their spouses; Grady and Esther, Welby and MiriLou, Troy and Shauna, Adam and Page, Noah and Whitney, Ralphie and Brian, Jed and Amber, Georgia and Wes, and Tonie and James, along with my grandchildren; Shelby, Dallin, Isaac, Ashton, Kira, Simon, Alana, Hanna, Seth, Aspen, Bridger, Molly, Max, Nate, Jane, Tad, Liv, Tru, Zen, Erin, Lucy, Nell, Jaguar, Ravin, Alexander, and Quinn. These people have tolerated me, loved me, and supported me through every difficulty. This was not possible without them. They have my love, respect, and gratitude. 


\section{ACKNOWLEDGMENTS}

Words cannot express my gratitude for the time, effort, and support of my

committee chair and saint, Dr. Gretchen Peacock. I also want to thank my committee members, Dr. Lisa Boyce, Dr. Clint Field, Dr. Mark Innocenti, and Dr. Donna Gilbertson. 


\section{CONTENTS}

ABSTRACT ...........................................................................................

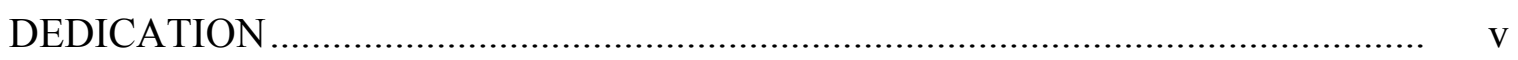

ACKNOWLEDGMENTS _........................................................................ vi

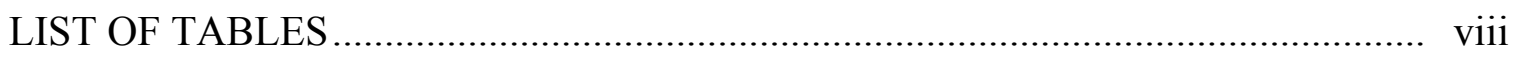

\section{CHAPTER}

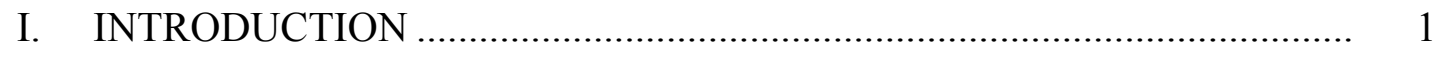

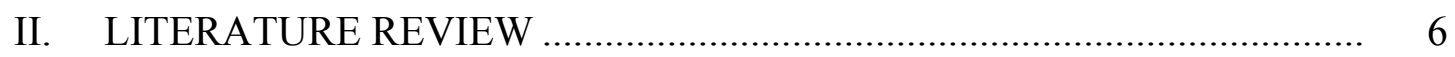

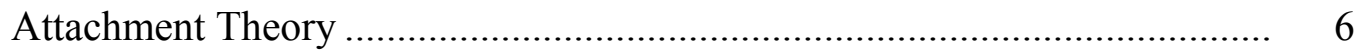

Assessment of Attachment.................................................................. 12

Parent Factors that Influence Attachment Security ................................. 20

Child Factors that Influence Attachment Security .................................... 22

Emotional and Behavioral Correlates of Attachment ................................. 23

Attachment in Children with Developmental Delays ............................... 26

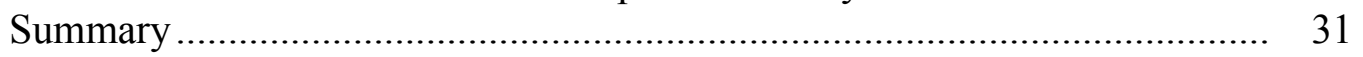

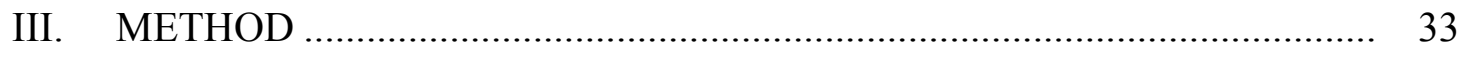

Participants ............................................................................. 33

Demographic Characteristics ........................................................... 33

Instruments......................................................................... 34

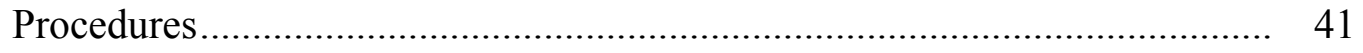

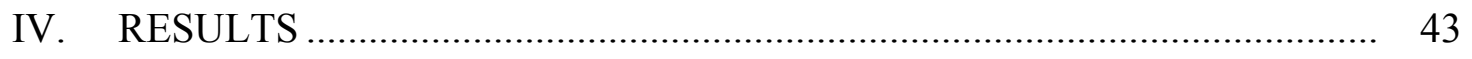

Descriptive Statistics and Preliminary Analyses ..................................... 43

Attachment in Children with Developmental Delays .................................. 45

Parent Factors that Predict Security .......................................................... 48

Child Factors that Predict Attachment Security....................................... 50

Stability of Attachment Security Scores for One Year's Time.................... 51

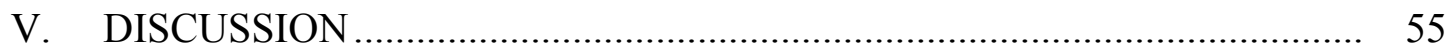


Security of Attachment in Children with Developmental Delays ................. 55

Maternal Predictors of Attachment ............................................................. 58

Child Predictors of Attachment ................................................................ 59

Stability of Attachment in Children with Developmental Delays .................. 61

Attachment as a Predictor of Behavior Problems in Children with Developmental Delays ..................................................................... 61

Limitations and Future Directions ............................................................ 62

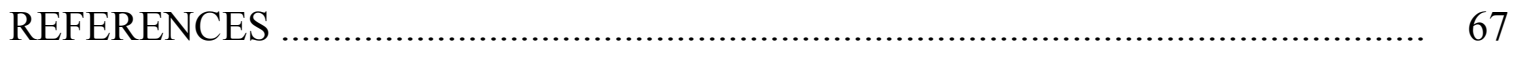

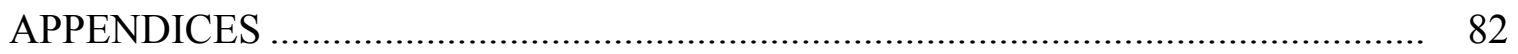

Appendix A: Time 1 Letter and Parent Questionnaire .................................. 83

Appendix B: Time 2 Letter and Parent Questionnaire …………………..... 86

Appendix C: Informed Consent............................................................. 89

Appendix D: Measures …………………………………………….... 92

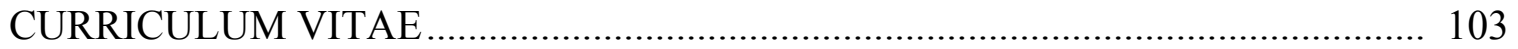




\section{LIST OF TABLES}

Table

1. Strange Situation Protocol .......................................................................... 13

2. Demographic Characteristics of Sample at Time 1 ..................................... 35

3. Descriptive Statistics for Measures.............................................................. 44

4. Percentages of Children in Each CAQ Attachment Category ........................ 45

5. Correlations Between Attachment, Time 1 Variables, and Time 2 Behavior Problems ................................................................................ 46

6. Percentages of Children in Each CAQ Attachment Category ........................ 47

7. Percentages of Children in CAQ Secure-Insecure Attachment Categories ....... 48

8. Contribution of Parent Factors to the Degree of Attachment Security

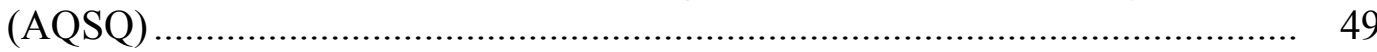

9. Contribution of Parent Factors to Secure Attachment (CAQ) ........................ 50

10. Contribution of Child Factors to Degree of Attachment Security (AQSQ)...... 51

11. Contribution of Child Factors to Secure Attachment (CAQ) ........................ 52

12. Changes in Attachment Security (CAQ) Over 1 Year's Time ....................... 53

13. Attachment Scores (Time 1) Prediction of Internalizing Behavior Problems

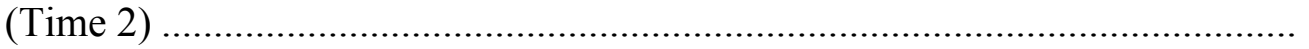

14. Attachment Scores (Time 1) Prediction of Externalizing Behavior Problems (Time 2) ....................................................................... 54

15. Attachment Scores (Time 1) Prediction of Behavior Problems (Time 2) ........ 54 


\section{CHAPTER I}

\section{INTRODUCTION}

Much research has been published in recent years regarding the importance of a secure mother-infant attachment for the healthy social and emotional development of children. Bowlby (1969/1982), who is credited with the origination of attachment theory, described attachment as the close emotional relationship between two persons. He proposed that the degree of secure attachment between a mother and her infant was shown by the amount affection shared by them and their mutual demonstration of desire to maintain proximity, especially in situation of distress (Bowlby, 1973).

Subsequent researchers have suggested that infants with highly secure attachments to their mothers experience a sense of belongingness (Oppenheim, KorenKari, \& Sagi, 1999), consistency, and trust (Cassidy, 2000). Researchers have found that when a secure attachment is present in infancy, behaviors of the child are likely to include high self-esteem, cooperation, social competence, management of aggression, emotional regulation, academic achievement, and an overall resilience to negative environmental risks (Bost, Vaughn, Washington, Cielinski, \& Bradford, 1998; Sroufe, Duggal, Weinfield, \& Carlson, 2000; Wittmer, Doll, \& Strain, 1996).

Although obtaining a secure attachment to their mother has been referred to as infants' primary developmental task (Peterson, 1987), some infants develop what Bowlby (1969/1982) described as insecure attachment to their mothers. This less desirable type of attachment is typified by less stable or absent affection between the mothers and their infants and less secure behaviors of seeking proximity to one another. Insecure 
attachment has been named as a significant risk factor for a number of emotional and behavioral disorders both in childhood and adulthood (Sroufe et al., 2000). Some researchers have hypothesized that virtually all social and emotional problems exhibited in early childhood are due to relational problems of lack of secure attachment with the primary caregiver (Raver \& Zigler, 1997).

A number of characteristics of both a mother and her infant have been found to influence the security of their attachment relationship. The mother's own attachment security in early childhood (Pederson, Gleason, Moran, \& Bento, 1998), the degree of stress experienced with parenthood and other life stressors (Waters, Hamilton, \& Weinfield, 2000) and the mother's psychological problems (Teti, Gelfand, Messinger, \& Isabella, 1995) are related to the degree of security or insecurity of a mother's attachment with her infant. Infants with a difficult temperament, medical problems in the first year of life, abuse, and/or separation from the attachment figure, appear to be more likely to develop an insecure attachment (Grizenko, 1994).

It has also been hypothesized that infants with developmental delays are more at risk than typically developing infants for insecure attachments to their mothers (e.g., Silber, 1989; Van Ijzendoorn, Goldberg, Kroonenberg, \& Frenkel, 1992; Wasserman, Lennon, Allen, \& Shilansky, 1987). Young children can experience developmental delays in different areas including speech/language, motor, cognitive and social emotional delays. Researchers have attempted to determine if attachment with their mothers, for infants with developmental delays is the same as that for typically developing children. The results of these studies have been mixed. Some researchers have suggested that the 
attachment process and security of attachment is the same in children with delayed and typical developmental patterns (e.g., Speltz, Endriga, Fisher, \& Mason, 1997). Other authors have indicated that a developmental delay interferes with interaction and proximity seeking between a mother and her infant and therefore the process of development of secure attachment is altered (Blacher \& Meyers, 1983; Lederberg \& Mobley, 1990; Vaughn \& Bost, 1999). Some researchers have found a higher incidence of insecure attachment between mothers and their infants with chronic illness and/or developmental delays (e.g., Greenberg, Speltz, Deklyen, \& Endriga, 1991; Mrazek, Casey, \& Anderson, 1987; Speltz, Greenberg, \& Deklyen, 1990), and others have suggested that a social-emotional delay, itself, may be the result of an insecure attachment (e.g., Sameroff \& Emde, 1989). Due to the possibility that attachment for children with developmental delays may be different and/or less secure than for children who are typically developing, attachment behaviors have become a primary focus for early intervention and infant mental health treatment (Maldonado-Duran, 2002; Zeanah, Boris, \& Leiberman, 2000). However, in order to better understand attachment in infants and young children with developmental delays, further study is needed.

One particular area in need of study is the relationship between attachment in infants with developmental delays and their subsequent behavior problems at preschool age. This need is indicated by researchers who have shown a relationship between insecure attachment in children who are typically developing and behavior problems in preschool, adolescence, and adulthood (e.g., Bohlin, Hagekull, \& Rydell, 2000; Park \& Waters, 1989). These studies highlight the need for early identification and treatment of 
children who may (without treatment) later engage in criminal or harmful acts toward people and institutions in our society. These studies, however, did not include children who had been identified at a young age as having developmental delays. Because children with developmental delays are considered at risk for emotional and behavior problems, studies of early influences on problem behaviors in this population seems paramount. Therefore, the purpose of this study was to add specific information to the literature available concerning attachment in young children with developmental delays. The following research questions were used to guide this study.

1. What percentage of children with developmental delays falls into each attachment category (using both the secure, avoidant, resistant, disorganized categorization and the global secure and insecure categories)?

2. What parent factors and child factors predict the pattern of security of attachment in young children (1 $1 \frac{1}{2}-2$ years) with developmental delays?

3. Are attachment security scores of children with developmental delays stable across one year's time?

4. Does attachment at age $1 \frac{1}{2}-2$ predict behavior problems one year later in young children with developmental delays?

In forming hypotheses, the past research in the area of attachment with both children who are typically developing and children with developmental delays has been considered. Likewise, researchers' findings that there is an association between the degree of attachment security and preschool behavior problems of children who are typically developing, have been taken into account. The following outcomes were 
hypothesized.

1. The percentage of insecure attachment rating of children with developmental delays will be higher than what is reported in the literature for children who are typically developing. A higher percentage of children with developmental delays will fall into the insecure-resistant category than the percentage reported for typically developing children.

2. Parent factors (parenting stress and psychological problems) will contribute to the variance in attachment so that parents reporting less stress and fewer psychological problems will report more secure attachments with their children.

3. Child factors (gender, temperament) will contribute to the variance in attachment so that children with easier temperaments and children who are girls will have more secure attachments.

4. Attachment scores will remain stable over one year's time.

5. Security of attachment scores will be inversely related to child behavior problem scores after one year's time. 


\section{CHAPTER II}

\section{LITERATURE REVIEW}

A review of literature was conducted in order to synthesize the available research results to meet the following objectives.

1. To provide the theoretical base for attachment theory.

2. To become aware of methods used to determine attachment security and insecurity.

3. To understand the correlates of secure and insecure attachment for children who are typically developing.

4. To review the current research on attachment in children with developmental delays.

\section{Attachment Theory}

Attachment is a construct that has been studied since the 1960s. Bowlby (1969/1982), a psychiatrist, used his observations of infants who were separated from their mothers to document the "grief reaction" that the infants appeared to exhibit with the separation. He theorized that the infants' behaviors were a manifestation of an emotional bond between infants and their mothers that he referred to as mother-infant attachment. Bowlby (1973) defined attachment as the close emotional relationship between two persons, characterized by mutual affection and a desire to maintain proximity. The primary attachment relationship between a mother and her infant, he postulated, is formed in the first years of life and remains relatively stable throughout 
childhood, adolescence, and adulthood. Mother-infant attachment, proposed Bowlby (1973) is a critically important process for the healthy emotional development of the individual. In his attachment theory, Bowlby (1969/1982) suggested that if a primary caregiver (in most cases, the mother) is consistently sensitive to her infant's cries or other signals of need, an attachment relationship begins to develop. By the last half of the first year, the infant begins to "have confidence" that his or her caregiver is emotionally responsive. According to Bowlby (1973), the infant's trust in the mother's positive responses leads to an internal representation within the infant of the mother-infant relationship as positive, rewarding, dependable, and safe. At the same time, the infant forms a representation of "the self" as worthy of love and care. This cognitive representation or working model (Bowlby, 1969/1982) is then generalized to the infant's expectations of other relationships and serves to guide the infant's behavioral reactions to distress. Thus, the working model becomes a source of continuity for infants in regard to their feelings, behaviors, and experiences. Bowlby (1969/1982) called the working model of this optimal and fundamental relationship a secure mother-infant attachment. He hypothesized that this secure working model becomes a cognitive framework for relationships throughout the child's life.

Bowlby (1969/1982) also observed that some infants developed a working model of insecure attachment when a mother was emotionally unavailable to her infant, or her sensitivity and/or responsiveness was inconsistent or negative in nature. The insecure working model of attachment also carried forth from the child's primary relationship to subsequent relationships for that individual throughout life. 
Bowlby's theory of attachment as a working model has been supported by research that shows the stability of the security of the mother-child relationship throughout childhood (Benoit \& Parker, 1994). Studies have also indicated that attachment security or insecurity is transferred to relationships with peers (Seibert, 2010), romantic relationships (Feeney, 2004), and life partners (Creasey \& Jarvis, 2009).

Researchers (e.g., Colin, 1996) have suggested that approximately $90 \%$ of the time, the primary attachment figure for the infant is the mother, although situations do exist in which a grandmother, father, or other caregiver serves as the attachment figure. Other authors (e.g., Colin, 1996; Schaeffer \& Emerson, 1984) have shown that attachments are often formed with more than one caregiver. In these cases, the security of the relationship may be somewhat different with each caregiver, but as a rule, if the attachment to the primary caregiver is highly secure, the attachment to other caregivers is also secure. Because almost all research has been focused on mother-infant relationships, this review of literature is focused only on the attachment relationship between mothers and their young children before the age of 3 years.

Bowlby’s (1969/1982) observations led him to believe that infants' working models, whether secure or insecure, influenced their behaviors when distressed. Bowlby and subsequent researchers (Ainsworth, Blehar, Waters, \& Wall, 1978) identified infant behaviors that are related to a positive mother-infant relationship and are assumed to be indicators of a high degree of attachment security. They are: a negative reaction to separation from the mother, the ability to be comforted and return to exploration with the mother near, proximity seeking, and infant actions that are referred to as secure base 
behaviors (Bowlby, 1969/1982). Secure base behaviors are shown when the infant ventures away from the mother in order to explore the environment, but checks back with the mother periodically in order to feel save, elicit approval or attention, and gain assurance of the mother's whereabouts. Proximity to the mother is consistently sought by more securely attached children when they are upset or frightened.

Infants with negative or disturbed relationships with their mothers show different behaviors, including either an intense or an indifferent reaction to separation from their mother, anger, or a mixture of those reactions upon the mother's return. These children, who are assumed to be more insecurely attached, seem to have either a coercive relationship with their mothers or might be seen as having no real relationship with their mothers. They are seen as clingy, angry, or unresponsive to their mothers during play. Infants with these more insecure attachments are typically inconsolable by their mothers when upset or frightened.

Bowlby (1969/1982) and others have proposed that these attachment behaviors can be interpreted as the manifestation of the infants' cognitive working models of the relationship they have with their mother, and simultaneously the representation they have of themselves (Mikulincer et al., 2003). Bowlby (1988) wrote, "the pathway followed by each developing individual and the extent to which he or she becomes resilient to stressful life events is determined to a very significant degree by the pattern of attachment developed during the early years" (p. 688). Subsequent researchers (e.g., Atkinson \& Zucker, 1997) have confirmed his theory, including the importance of the development of highly secure mother-infant attachments. Study of the attachment relationship has led to a 
greater understanding of the emotional health of very young children.

Mary Ainsworth was one of the individuals (Ainsworth et al., 1978) who continued Bowlby's work. She was interested in both maternal and child behaviors. The sensitivity and responsiveness of the mother are vital, according to Ainsworth and colleagues, for the secure attachment of young children.

Ainsworth and her colleagues (1978) were the first to attempt to categorize secure and insecure mental representations of attachment. In their studies (Ainsworth et al., 1978) they found that approximately $60 \%$ of the infants in her sample, which was taken from throughout North America, exhibited behaviors that fell into a category she identified as securely attached. Infants in this category were most likely to have a mother who was warm, sensitive, and responsive to signals given by the child. In situations of stress, infants displayed little or no anger toward their mother and after receiving comfort would soon return to play.

The majority of the remaining $40 \%$ of the infants in studies by Ainsworth and associates (1978) were identified as insecurely attached. Mothers of these infants lacked sensitivity to the feeling states of their children and were either directive and controlling or unresponsive to their baby's cues. These insecure infants did not use the mother as a safe haven in times of stress, nor did they use their mother as a secure base from which to explore their environment.

Ainsworth and others' (1978) two different insecure categories were insecureavoidant (or anxious-avoidant) and insecure-resistant (also called anxious-ambivalent). The insecure-avoidant infants were the most likely to have an unresponsive caregiver. 
These babies tended to ignore (avoid) their mothers and withdraw from their mothers' attempts to comfort them. On the other hand, insecure-resistant children most often had a care giving environment in which they experienced both positive and negative interaction with their mothers. The problem was that they could not tell which to expect. These children were likely to show some anger (resistance) toward their caregiver in stressful situations, and were often difficult to sooth. Under stress, these infants fluctuated from aggressiveness and anger, to coy, needy and manipulative behavior.

Sometime later, Main and Solomon (1999) suggested that it was possible to identify another category of insecure attachment in some of the children who did not fit into either the avoidant or resistant categories. Referred to as insecure-disorganized/ disoriented attachment, this has become the fourth major category of attachment. This category was found to be related to both "frightening" and "frightened" parenting styles (Abrams, 2001). Mothers of insecure-disorganized/disoriented infants tend to be either emotionally or physically abusive (frightening) or live in a state of fear or victimization themselves (frightened). Jacobsen, Hibbs, and Ziegenhain's (2000) research showed that a mother's high level of expressed emotion (intrusive and hostile maternal behavior) was related to a disorganized attachment style in her child. Children with this classification appear to lack a coherent or organized strategy to cope with stressful situations. When presented with those situations, they may appear to be depressed or exhibit mixtures of avoidance, anger, fear, and attachment behaviors. Children with this attachment style were found to lack stress management strategies and to aggressively act out or externalize behavior problems. Children with behaviors in this category have also been found to 
show medical failure-to-thrive (Ward, Lee, \& Lipper, 2000) and dissociative behavior in later life (Van IJzendoorn, Schuengel, \& Bakermans-Kranenburg, 1999). It has been hypothesized that the negative behaviors associated with insecure attachments are actually adaptive behaviors. From an evolutionary perspective, these behaviors may be exhibited to elicit caregiving by adults, which, in turn, enhance the probability of survival (Balbernie, 2010). So although the research is clear that secure mother-child attachment is protective and insecure mother-child attachment is a risk factor in regard to prosocial behaviors (Bauminger \& Kimhi-Kind, 2008), this perhaps does not reflect successful adaptation and survival of an individual despite negative circumstances.

Although traditionally attachment has been conceptualized in a categorical manner, a number of researchers have suggested that it might better be understood as a dimensional construct. Waters and Deane (1985) have placed attachment on a linear continuum from secure to insecure, and Gardner, Lamb, Thompson, and Sagi (1986) found that differences between resistant and avoidant children are often weak and unreliable. Fraley and Spieker (2003) have suggested that the construct is better described as ranging from insecure, avoidantly attached (more distancing), youngsters on one end of the continuum to insecurely anxiously attached children on the opposite end, with securely attached children in the middle. It seems that the construct of attachment is still in development, and the methods of measuring that construct are developing as well.

\section{Assessment of Attachment}

One of the first measures of attachment was the Strange Situation (Ainsworth et 
al., 1978). Since Bowlby's (1969) theory was based upon observations of mothers and infants, Ainsworth used observations of behavior for her assessment process. In the Strange Situation, behaviors were coded and infants were assigned attachment classifications during a contrived laboratory separation procedure.

The Strange Situation involved two brief (3-6 minute) separations from the mother (or primary caregiver) in an unfamiliar setting. Behaviors of both the infant and the mother were coded at separation and at reunion (see Table 1). Although Ainsworth and colleagues (Ainsworth et al., 1978) recognized that observation in the child's natural environment would be a more valid measure of attachment, the Strange Situation provided a more objective and controlled measure. The Strange Situation has, therefore, become the "gold standard" of the measurement of attachment.

\section{Table 1}

Strange Situation Protocol

\begin{tabular}{|c|c|c|}
\hline Episode & People present & Procedure \\
\hline 1 & $\mathrm{~B}, \mathrm{C}, \mathrm{E}$ & $\begin{array}{l}\text { E shows } C \text { where to put } B \text { and where to sit, then leaves. If necessary, } C \text { gets } \\
B \text { to start playing with toys. }\end{array}$ \\
\hline 2 & $\mathrm{~B}, \mathrm{C}$ & C not to initiate interaction, but may respond. \\
\hline 3 & $\mathrm{~B}, \mathrm{C}, \mathrm{S}$ & $\begin{array}{l}\mathrm{S} \text { enters, sits quietly for a minute, talks with } \mathrm{C} \text { for a minute, and engages } \mathrm{B} \\
\text { in interaction or play for a minute. }\end{array}$ \\
\hline 4 & $\mathrm{~B}, \mathrm{~S}$ & $\begin{array}{l}\mathrm{C} \text { exits, } \mathrm{S} \text { lets B play. If B needs comfort, } \mathrm{S} \text { tries to provide it. If } \mathrm{B} \text { cries } \\
\text { hard, episode can be terminated early. }\end{array}$ \\
\hline 5 & $\mathrm{~B}, \mathrm{C}$ & $\begin{array}{l}\text { C calls to B from outside the door, enters, greets B, and pauses. If B needs } \\
\text { comfort, C may provide it. When B is ready to play with toys, C sits in her } \\
\text { chair. If B is very upset and needs extra time with C, episode can be } \\
\text { prolonged. }\end{array}$ \\
\hline 6 & B & $\mathrm{C}$ exits. $\mathrm{B}$ is left alone. If $\mathrm{B}$ cries hard episode can be terminated early. \\
\hline 7 & $\mathrm{~B}, \mathrm{~S}$ & $\begin{array}{l}\mathrm{S} \text { enters, greets } \mathrm{B} \text {, and pauses. If } \mathrm{B} \text { is } \mathrm{OK}, \mathrm{S} \text { sits. If } \mathrm{B} \text { needs comfort, } \mathrm{S} \text { tries } \\
\text { to provide it. If B cries hard, episode can be terminated. }\end{array}$ \\
\hline 8 & $\mathrm{~B}, \mathrm{C}$ & $\begin{array}{l}\text { C calls to B from outside the door, enters, pauses, picks B up, comforts B if } \\
\text { necessary, and lets B return to play when ready. }\end{array}$ \\
\hline
\end{tabular}


Ainsworth became more and more specific in the coding of behaviors in the Strange Situation. Within the original three categories (secure, insecure-avoidant, insecure-resistant), she outlined eight subgroups into which infant patterns of attachment behavior could be classified (Ainsworth, 1985). Later, the coding of Main and Solomon's (1990) insecure-disorganized/disoriented category was added to the Strange Situation, as well. Yet even with this addition, there are still a number of children whose attachment behaviors do not fit into any of these categories. Identification of attachment security using the Strange Situation is a complex procedure, and by definition causes distress to both the mother and the infant.

In 1985, Waters and Deane reported the development of a different measure of attachment. Based upon the attachment behaviors that Ainsworth and her colleagues (1978) identified broadly as either secure or insecure, Waters and Deane (1985) created a method that was meant to simplify the conceptualization of attachment to that of a continuum from secure to insecure, and eliminate the need for the Strange Situation. With their instrument, the Attachment Q-sort, a child's ongoing observed behaviors were used to quantify the degree of attachment security. The degree of secure and insecure attachment identified by the Attachment Q-sort has been found to be correlated with the Strange Situation secure and insecure categories (Teti, Nakaqawa, Das, \& Wirth, 1991; Van Bakel \& Riksen-Walraven, 2004).

The Attachment Q-sort is administered to someone who is familiar with the home situation and the mother-child relationship. It consists of 90 cards, each of which contains a description of child behaviors. Behaviors that are characteristic of securely and 
insecurely attached children are included, as well as a small number of distracter cards that describe non-attachment child behaviors. For the recommended observer Q-sort, the assessment requires two observers to make two home visits of 90-120 minutes each, and additional observations are sometimes needed. The card sorting portion of the assessment requires another 45-90 minutes. Cards describing child behaviors are sorted into 9 piles of 10 cards each. The cards are first ordered in the 9 piles by the degree to which behaviors are like or unlike the child. Next the cards within each pile are ordered along the same dimension. These 90 sequenced cards are then compared with those of a prototype of a securely attached infant. A score is given to indicate to what degree the infant's behaviors match the secure infant prototype.

The Attachment Q-sort (Waters \& Deane, 1985) was later implemented using mothers as the observers (Tababulsy, Avgoustis, Phillips, Pederson, \& Moran, 1997; Teti \& McGourty, 1996). Reliability between the observer and mother completed Q-sorts was found to be .55 and .57 , although this degree of reliability is not high, a number of authors have used the mother completed Attachment Q-sort to measure attachment security. In this case additional observation time is not needed, but it still takes approximately 45-90 minutes to administer. Scoring is done through a comparison of achieved scores compared to those of a hypothesized optimally securely attached child. Thus time involvement in both administration and scoring make the Attachment Q-sort difficult to implement on a routine basis in early intervention or clinical settings.

Considering the evidence regarding the importance of secure mother-child attachment, researchers and practitioners have developed a number of attachment 
intervention programs for use in early intervention, infant mental health and at-risk programs throughout the country (e.g. Arhin, 2006; Bialy, 2006; Klopfer, 2009; Svanberg, 2009). There is growing evidence that attachment-based interventions can significantly enhance the quality of the parent child relationship and the security of attachment in at-risk populations (Berlin, Ziv, Amaya-Jackson, \& Greenberg, 2005; Heinicke, Rineman, Ponce, \& Guthrie, 2008; Lieberman \& Van Horn, 2007; Marvin, Cooper, Hoffman, \& Powell, 2002; Oppenheim \& Goldsmith, 2007). Some of these intervention programs use either the Strange Situation or the Attachment Q-sort to assess attachment security, but in the interest of the best use of time, many interventions are conducted without the assessment of attachment security, or by inferring the security or insecurity of attachment through the results of other measures (Murphy, 2010). A number of instruments have been developed in an attempt to measure mother-child attachment quickly and effectively. Besides the Strange Situation and the Attachment Q-sort, there are currently seven other measures which are purported to specifically measure attachment security between mothers and infants. These measures are: the California Attachment Procedure (Clarke-Stewart, Goossens, \& Allhusen, 2001), the Maternal Postnatal Attachment Scale (Condon \& Corkindale, 1998), the Mother-Infant-ToddlerAttachment System (MITAS; Egblomasse, 1999), the Child Attachment Questionnaire (CAQ; Huggar, 1999), the Differential Social Reaction Procedure (Klein, Suwalsky, McCarthy, \& Gist, 1982), the Maternal Attachment Inventory (Muller, 1994), and the Attachment Q-Sort Questionnaire (AQSQ; Robinson, 1995). None of these measures have been used extensively and psychometric information is limited. 
Both the Maternal Attachment Inventory and the Maternal Postnatal Attachment scale were developed to measure attachment in a unidirectional manner from mother to infant, and do not take into account infant behaviors. These maternal report measures have been mainly used in medical settings and are not consistent with the Ainsworth (1985) and Bowlby (1969/1982) theoretical assessment of both maternal and child behaviors.

Like the Strange Situation, the California Attachment Procedure and the Differential Social Reaction Procedure are conducted in a laboratory setting. In the California Attachment Procedure mothers and infants are not separated, but are exposed to a number of frightening stimuli for the child (e.g., a mysterious loud noise, a mechanical robot). In the Differential Social Reaction Procedure, first strangers attempted to engage infants in interactive play, followed by the mother interacting with the child in the same way. Limited reliability and validity have been reported for both of these laboratory procedures (Clarke-Stewart et al., 2001; Klein et al., 1982).

The MITAS was the result of a research dissertation in which Egblomasse (1999) studied the relationships between mother-child interactions and maternal feelings and perceptions about their babies. This measure's reliability and validity were not evaluated.

The CAQ is based directly upon Bowlby's and Ainsworth's research and the differences in child attachment behaviors in the Strange Situation. This maternal report measure was developed and used as part of a dissertation study of the emotional assessment of infants, toddlers and preschoolers (Huggar, 1999). The questionnaire describes the typical infant attachment behaviors of each of the Ainsworth and 
colleagues' (1978) and Main and Solomon (1990) categories, and asks the mother to indicate which group of behaviors best typified her child. Huggar and Curtis (1999) suggested the measure is valid based upon their findings that when comparing children in normal and clinical groups on the CAQ, there were significantly more insecurely attached children in the clinical group. They also found that children identified as insecurely attached using this measure had significantly more behavior problems, as measured by the Child Behavior Checklist (Achenbach, 1992). Primary caregiver insecure classification as measured by the Relationship Questionnaire (Bartholomew \& Horowitz, 1999) was also related to insecure attachment on this measure. This instrument has not yet been validated with Strange Situation scores.

The AQSQ, developed by Robinson (1995), was created for use in clinical research (Robinson, Rankin, \& Drotar, 1996) as a more useable adaptation of the Attachment Q-sort (Waters \& Deane, 1985). The AQSQ, as the Attachment Q-sort, is based upon observable attachment behaviors of the child described by Bowlby (1969/ 1982). "Attachment behaviors" are those that increase proximity to or maintain contact with the attachment figure (the mother). They are understood to be organized with respect to an internal system of control (the attachment system) that has the adaptive function of protection and set goal of physical proximity to the mother (Solomon \& George, 1999a). For this measure, 12 items, which were found by Vaughn and Waters (1990) to discriminate between secure and insecure attachment, are rated by mothers on a Likert scale. A similar scale was employed by Waters in his original Attachment Q-sort (1985). The construct validity of this measure is supported by research which indicates similarity 
between percentages of children assigned to secure and insecure categories by this measure and those on the standard Attachment Q-sort and by lower frequency of hospital visits by mothers to children who had been rated as having insecure patterns of attachment on the AQSQ (Robinson et al., 1996). Earlier research had established that parents who visited their ill children less also displayed unsatisfactory relationships with their children (Prugh, Staub, Sands, Kirshbaum, \& Lenihan, 1953).

Due to an abundance of research proclaiming the importance of mother-infant attachment, and the association between attachment and parent-child interaction and maternal sensitivity, a number of interactional coding systems and questionnaires (e.g., Baird, Haas, McCormick, Carruta, \& Turner, 1992; Pederson \& Moran, 1995) have been developed. Although these systems are meant to measure behaviors associated with attachment, they are not purported to measure the attachment construct, and research on the psychometric properties is limited. The measurement of both child and maternal representation of attachment and its correlates continues to be a focus of research in child development and treatment.

According to Solomon and George (2008), the validity of an attachment measure is often assessed by the measure's relationship to a group of core predictors. These predictors are a positive relationship with the caregiver's accessibility and responsiveness to the child, the stability of the results of the measure over time, how well the measure predicts other important aspects of development (e.g., autonomy, social competence), and the ability of the measure to obtain similar results across cultures. So far, the Strange Situation and the Attachment Q-sort are the only measures to be tested against and found 
to meet these criteria. Furthermore, although it is recognized in the literature that a briefer and more usable, yet effective measure of attachment is needed, none of the above brief measures have been studied in regard to Solomon and George's (2008) criteria or in comparison with either the Strange Situation or the Attachment Q-sort.

One of the greatest impacts of the lack of validation of brief measures of attachment is apparent in early intervention programs. These programs' goals are to either remediate or decrease the impact of a developmental delay. It is important to be able to assess, quickly and effectively, all areas of possible delay. Because attachment security has been found to make such a big impact on a child's mental health and behavior, a more early intervention friendly measure of attachment is needed in order to provide intervention in with less secure attachment relationships. More research is necessary to in order to validate brief measures of attachment.

\section{Parent Factors that Influence Attachment Security}

From the beginning, with Bowlby (1969/1982) and Ainsworth's work (Ainsworth et al., 1978), researchers have emphasized the association between sensitive maternal behaviors and secure attachment. Some authors have defined and measured attachment through mothers' reports of their maternal feelings and behaviors (Condon \& Corkindale, 1998; Scopesi, Viterbori, Sponza, \& Zucchinetti, 2004). Maternal behaviors related to secure mother-infant attachment are the reading of a baby's signals or interpreting the infant's needs and consistently responding to those signals (Nicely, Tamis-LeMonda, \& Grolnick, 1999; Werner \& Smith, 1992), positive interaction with the child (Harnish, 
Dodge, \& Valente, 1995), and empathic understanding or emotional matching (Oppenheim, 2001). It is understandable that it is difficult for mothers to exhibit these behaviors when there are interfering factors in their lives. Two factors named in the literature that affect attachment security are parenting stress and psychological problems of the mother (e.g., Hubbs-Tait et al., 1996; Teti \& Gelfand, 1997).

Considerable research has focused on maternal depression and its effect on the cognitive, physical, and emotional health of children who are otherwise typically developing (e.g., Jameson, Gelfand, Kulcsar, \& Teti, 1997; Kaplan, Bachorowsk, \& Zarlengo-Strouse, 1999). Multiple studies have shown that depressed mothers' interactions with their infants are negatively affected by their depressed mood (Campbell, Cohn, \& Meyers, 1995; Edhborg, Lundh, Seimyr, \& Widstrom, 2001; Field, 2002). Other studies show that attachment classification is affected by maternal depression, with depression predicting insecure attachments (Lyons-Ruth, Easterbrooks, \& Cibelli, 1997; Martins \& Gaffan, 2000; Teti et al., 1995). Additional maternal psychological problems that have been found to interfere with secure attachment are: anxiety, bipolar disorder, schizophrenia, and other psychotic and personality disorders (Atkinson et al., 2000; Garmezy, 1987; Lyons-Ruth, Alpern, \& Repacholi, 1993; Manassis, Bradley, Goldberg, Hood, \& Swinson, 1995). When a mother is dealing with personal mental health problems, her child's need are often either ignored or dealt with in negative ways (Cunningham, Harris, Vostanis, Oyebode, \& Blisset, 2004). Consistent, responsive, and dependable caregiving can be difficult for these mothers given their own struggles. Life stress and parenting stress have also been found to interfere with the 
development of secure attachment between mothers and their children who are typically developing (Hadadian \& Merbler, 1996). Again, it seems logical that the amount of emotional strength of the mother can be depleted by stressful events in her life, including the stress of caring for a new child. This depletion, then, results in an impaired ability to consistently and positively respond to the needs of an infant.

\section{Child Factors that Influence Attachment Security}

Characteristics of the child may also impact the attachment relationship. One characteristic that seems to influence attachment is the child's temperament (Calkins \& Fox, 1992). In fact, the concepts of attachment and temperament are so intertwined that some researchers have questioned whether they are parts of a universal mechanism within a developing child (Mangelsdorf \& Frosch, 2000; Vaughn \& Bost, 1999). As with attachment research, research of temperament began in the 1960s. Temperament as defined by Thomas, Chess, and Birch (1968), refers to the consistent behavioral style an individual manifests beginning at a very early age. In their groundbreaking research, these authors were the first to report a categorization of infant temperament into three groups based upon behaviors exhibited in the first months of life. The temperament categories of easy, difficult and slow-to-warm-up, are based upon the infant or child's emotionality, adaptability, sociability and intensity. Children with easy temperaments are more likely to have more secure attachments with their mother, while those with difficult or slow-to-warm-up temperaments are more often found to be insecurely attached. The characteristics of the mother and the temperament of the child can interact in either 
positive or negative ways (Mangelsdorf, McHale, Diener, Goldstein, \& Lehn, 2000;

Weber, Levitt, \& Clark, 1986). Rosen and Rothbaum (1993) proposed that the goodness

of fit or compatibility of maternal temperament and behaviors which are directed toward the child's temperament style is the best predictor of a high degree of attachment security.

\section{Emotional and Behavioral Correlates of Attachment}

Not only do child factors relate to the development of attachment in children who are typically developing, but the type of attachment may predict later child performance. A number of studies show that the degree of attachment security is related to the actual behaviors of the child. Researchers have suggested that this relationship continues throughout the child's development. Beginning with mother-infant attachment and preschool behavior, it appears clear that a more secure attachment in infancy is related to subsequent preschool competence in children. The results from research with children who are typically developing have indicated that children identified as highly securely attached have more socially appropriate behaviors than those categorized as more insecure (Schneider, Atkinson, \& Tardif, 2001). In the preschool setting, securely attached children have been shown to have more friends (Park \& Waters, 1989), have fewer conflicts with peers, exhibit better self-regulatory behavior (Easterbrooks \& Goldberg, 1990), and be more likely to interpret aggressive acts by other children as accidental or unintentional (Wartner, Grossman, Fremmer-Bombik, \& Suess, 1994). In addition, preschool children who are typically developing who have highly secure 
attachments engage in more appropriate symbolic and cooperative play (Bost et al., 1998; Kerns \& Barth, 1995) and are less aggressive and more popular among their peers (Wu \& Zou, 1995).

Conversely, if a child's attachment is insecure, he or she will be less likely to be able to manage stress in appropriate ways and more likely to exhibit acting out or externalizing behaviors in the preschool setting (Greenberg, 1999; Van IJzendoorn et al., 1999). These behaviors may include noncompliance to adult requests, impulsivity, hyperactivity, temper tantrums, and aggression (Greenberg et al., 1991). Research recently has confirmed an association between insecure attachment and physiological as well as behavior problems. Burgess, Marshall, Rubin, and Fox (2003) found that an infant's avoidant attachment style was predictive of a lower heart rate and higher respiratory sinus arrhythmia (as well as more behavior problems) than children with secure attachment styles. Brain activity EEGs conducted while individuals with insecure attachments were sleeping has shown anomalies similar to those found for patients experiencing chronic pain (Sloan, Maunder, Hunter, \& Moldofsky, 2007).

The insecure-disorganized/disoriented attachment style (shortened to disorganized) has been studied extensively. In a meta-analysis, Van IJzendoorn and associates (1999) examined the relationship between a child's disorganized classification of attachment and behavior problems in preschool. Twelve studies were selected for analysis. All of the studies were conducted with children whose attachment to their mothers was classified as insecure-disorganized in early infancy (12-18 months of age). The combined effect size across studies was .29, which indicated a small association 
between disorganized attachment and preschool behavior problems. Problem behaviors included lack of stress management and presence of externalizing behaviors. More recent studies have supported the findings of this meta-analysis, showing stronger relationships between a disorganized attachment style and poor judgment, multiple fears, depression, tantrums, noncompliance, aggression and impulsiveness (Lyons-Ruth \& Jacobvitz, 2008; Pauli-Pott, Haverkock, Pott, \& Beckman, 2007).

The results of this research indicate that in the population of children who are typically developing, the degree of mother-child attachment security, identified at or before preschool age, is associated with preschool social behavior. There are similar findings that connect attachment and behavior in middle childhood and adolescence. Researchers have found that older children who were securely attached to their mothers in infancy will have a greater ability to understand negative emotions, resist temptation and develop conscience (Laible \& Thompson, 2000). Children with a high degree of secure attachment are more likely to go on to be effective problem solvers and express less negative affect than their insecurely classified peers (Easterbrooks \& Goldberg, 1990).

Secure attachment to a primary caregiver appears to act as a protective factor for a number of future problems, even in the most negative of situation. In 1989, Werner published the results of her longitudinal study of 678 low-income, multi-problem, highrisk families in Hawaii. She found that 72 of the children raised in these adverse circumstances remained resilient, which in this case meant being free of academic and behavior problems. In her study, she identified a small number of protective factors that 
seemed to be predictive of the 72 children's positive outcomes. Highly secure motherinfant attachment was identified as one of these protective factors. In contrast, insecure attachments between young children and their mothers predicted negative outcomes.

\section{Attachment in Children with Developmental Delays}

Considering the importance that attachment appears to play in the healthy mental and social development of children who are typically developing, it is important to study this maternal-infant relationship and its effects in children with developmental delays as well. The research conducted to date has produced mixed results regarding the development and patterns of attachment in children with developmental delays. In a literature review of 15 studies of newborn to 42-month-old children with disabilities, Blacher and Meyers (1983) found that there were higher percentages of infants and young children with disabilities reported to be insecurely attached than the percentages previously reported for children without disabilities. These authors discussed the difficulty in assessment of attachment behaviors in the children studied. Because of the challenges that some disabilities present in the standardized procedures of the Ainsworth Strange Situation and since these procedures have not been validated for use with children with various developmental delays, the Strange Situation was not used in all studies. Attachment security was determined in a variety of ways including an adapted Strange Situation, nonstructured observations in the home, and clinical interviews with mothers of the children with developmental delays. Regardless of difficulty in measurement, the opinion of the authors (Blacher \& Meyers, 1983) suggests that unique 
developmental problems in children with disabilities result in delayed, dulled, or disordered attachment.

In a meta-analysis of the security of attachment of 12-50 month-old children with diagnosed problems and 12- to 24-month-old children without problems (Van IJzendoorn et al., 1992) researchers found that the attachment classifications of children with problems did not differ significantly from those without problems. However, there was an overrepresentation of children with disabilities who were classified as insecuredisorganized. Despite the opinion of authors who believe that the Strange Situation is inappropriate for some children with some types of disability, for this meta-analysis, studies were chosen only if attachment classification was determined by the Strange Situation or slightly modified separation-reunion procedure. Van IJzendoorn and colleagues' (1992) results indicated that maternal factors (e.g., positive interaction and sensitivity) were more predictive of attachment security than child factors (diagnosis or disability). Although this seems to contradict the previous findings, it was noted by the authors that the impact of the child's disability on the mother's behavior was not examined.

As was reported in the 1980's (Blacher \& Meyers, 1983), more recent studies have also shown a higher likelihood of insecure attachments for children with disabilities (Bradley, Whiteside, Mundfrom, 1994; Hanson \& Spratt, 2000). Janssen, Schuengal, and Stolk (2002) reported an increased incidence of insecure attachment for individuals with intellectual disabilities. Insecure attachment, they reported, combined with environmental stress predicted challenging behaviors into adulthood. Clements and Barnett (2002) 
completed a study of attachment in toddlers with congenital abnormalities. They compared children with neurological impairments (e.g., cerebral palsy, epilepsy, myelomeningocele, hydrocephalus) to those with non-neurological birth defects (e.g., cleft lip, Pierre Robin syndrome, craniofacial anomaly, limb deficiency). These authors found a higher degree of insecure attachment in children with neurological impairments. They suggested that a child's medical problems influence parenting, parent-child interaction, and child attachment. Howe (2006) theorized that disability, like temperament, was a child factor that "affects levels of parental stress, quality of caregiving and therefore security of attachment."

The research regarding temperament in children with developmental delays is not clear regarding whether or not there are temperament differences in children with developmental delay. Heffernan, Black, and Poche (1982) found the distribution of a group of infants and toddlers with neurological impairments to be similar to the standardization sample in clusters of easy, difficult and slow-to-warm-up temperament styles. A more recent study of children with intellectual delays, however, indicates that parental ratings for these children are lower in the area of sociability than ratings of children who are typically developing (Zion \& Jenvey, 2006). In addition, a sample of boys with Fragile X Syndrome was scored as showing more anger and sadness than boys without the syndrome (Shanahan, Roberts, Hatton, Reznick, \& Goldsmith, 2008). Children with velocardial facial syndrome (a genetic disorder that usually includes heart defects, defining facial characteristics, and mild mental retardation) were rated as more difficult than children who are typically developing (Antshel et al., 2007). Temperament 
style may also affect outcomes for children with developmental delay. Huntington and Simeonsson (1993) found that infants and young children with disabilities and an easy temperament adapted much more quickly to their disability and to medical treatments than those with difficult temperaments.

Clear information regarding the degree of attachment security and the nature of attachment security in children with developmental delays is still unfolding. Research by Huebner and Thomas (1995), which examined the maternal attachment process for children with developmental delays, may lend insight into this area. These authors suggested there are more factors involved in attachment for children with developmental delays than there are for children who are typically developing. Early separations in the form of hospitalizations or traumatic medical experiences are more likely for infants with developmental delays. Infants who are born prematurely (who often are later identified as developmentally delayed) are more likely irritable and cause additional stress for their mothers. Mangelsdorf and colleagues (1996) found that approximately half of infants born medically at-risk develop insecure attachment relationships. Inability to change head position, to make eye contact or to focus attention on the mother may interfere with attachment. A disability may affect the child's emotional and verbal expressiveness, making it difficult for parents to interpret child signals or gain enjoyment from interaction (Barden, Ford, Jensen, Rogers-Slayer, \& Slayer, 1989).

As described above, a child's developmental delay can likewise affect parenting. Rather than celebrating the infant's birth, parents and families of children with developmental delays may instead be feeling shock, disbelief, grief, and dilemmas 
concerning medical bills. Discovering that one's child has a disability has been identified as a major stress and is compared to grieving for a lost child (Marvin \& Pianta, 1996; Sheeran, Marvin, \& Pianta, 1997). This emotional state of grieving may interfere with a mother's ability to provide consistent and sensitive care. Although for the child with an impairment, a developmental delay, or disfigurement, parental protection and sensitivity is all the more crucial for the child to survive and thrive, a parent may be emotionally unable to provide what the child needs. Along with trying to deal with their own feelings, mothers may be required to change or adapt their interaction behaviors for the deficits in interaction skills of their babies (Blacher \& Bromley, 1987; Tannock, 1988). It was suggested by Howe (2006) that lower attachment security in children with developmental delays may be due to the interaction between the child with disabilities and the caregiver's state of mind regarding attachment to a child with developmental problems. Hueber and Thomas (1995) reported that a child's disability often interferes with neurobiological functioning, which then interferes with attachment. Consequently, it is not surprising that parents of children with disabilities have been observed to be less sensitive and responsive to their children (Atkinson et al., 1999; Endriga, Speltz, Maris, \& Jones, 1998), which may lead to less secure attachment relationships.

Although study results still vary, it is now generally accepted that the motherchild attachment relationship in children with developmental delays may be different than the same relationship in children who are typically developing. It appears there may be several possibilities regarding the process of attachment in children with developmental delays. First, maternal-infant attachment may develop similarly to attachment with 
children who are typically developing, but is more difficult to measure. Second, motherchild attachment may be more likely to be insecure for children with developmental delays due to the child's delay or the mother's stress, attitude or behavior because of the delay. Or it is possible that either the attachment behaviors of the child or the process by which attachment is attained in qualitatively different for a mother and her child with a developmental delay.

Notwithstanding the difficulties attachment may pose for mothers and children with developmental delays, researchers have suggested that a secure attachment in a child with a developmental delay may be crucial for future adjustment and mental health. AlYogon's research (2003) indicated that in children with mild developmental delays, secure attachment was a protective factor from developing a high level of loneliness and a low sense of cohesion. Huebner and Thomas (1995) found evidence that if children with developmental delays had insecure attachments to their mothers, they were two to four times more likely to show psychopathology later in life. Likewise, Clegg and Sheard (2002) found that children and adults with intellectual disabilities who had insecure attachments with their parents were more likely to exhibit challenging behaviors, and Wellemsen-Swinkels, Bakermans-Kranenburg, Buitelaar, Van IJzendoorn, and England (2000) found that children with pervasive developmental disorders who had secure attachments scored higher on measures of social skills.

\section{Summary}

It is clear that attachment theory has become a well established explanation of the 
mother-child relationship for children who are typically developing. Based upon Bowlby's theory (1969/1982), mother-infant attachment security was first studied and measured with children who are typically developing through the use of the Strange Situation. To improve utility, other measures have been developed and used in research studies.

In understanding attachment theory it is important to recognize that characteristics of both the mother and the infant have been found to be associated with the security of their attachment with one another. These characteristics appear to either contribute to or interfere with the normal development of secure mother-infant attachments.

Research has suggested that a developmental delay in children may affect either the acquisition or the degree of attachment security in the mother-child relationship. Additional research is necessary to more fully understand attachment in children with developmental delays.

Of particular interest for this study is the research that indicates that there is an association between the security of maternal-child attachments and children's behavior at preschool age for children who are typically developing. Although Hueber and Thomas (1995) hypothesized a similar relationship in children with developmental delays, there is currently no empirical research on attachment and subsequent behavior problems in this population. The understanding of this association could provide needed information for the improvement of early intervention services to children with developmental delays throughout the country. 
CHAPTER III

METHOD

\section{Participants}

Participants in this study were the mothers of young children ages $1 \frac{1 / 2}{2}$ to 2 years who were identified as having a developmental delay by personnel from an early intervention program in northern Utah. Approval was obtained by both the early intervention program coordinators and the Institutional Review Board (IRB) at Utah State University. Although 98 mothers agreed to participate in this study, only 74 returned completed questionnaires. In this initial sample (Time 1), mothers completed a demographic questionnaire in addition to seven standardized measures of maternal and child characteristics. The sample at Time 2 was reduced to 56 children due to parental non-response. The following section describes the demographic information of the initial Time 1 sample, as well as the subsample for whom measures at both Time 1 and Time 2 are available. Demographic data provided by mothers of children with developmental delays were presented earlier in Table 1. Information concerning medical diagnosis and type of developmental delay was obtained from assessment information (Early Learning Assessment Profile-ELAP scores) and medical histories contained in Early Intervention files.

\section{Demographic Characteristics}

For the total Time 1 sample, more than two thirds of the children with 
developmental delays were male. The ethnic makeup of the sample was primarily Caucasian with $95 \%$ of the mothers reporting their ethnicity as Caucasian while $88 \%$ of the children were identified as Caucasian. Eighty-two percent of mothers in the initial sample were married and the average education level for the mothers (as well as the fathers) fell into the category indicating they had attended some college but had not attained a bachelor's degree. The mean household income for the sample was in the $\$ 35,000-\$ 50,000$ per year range with $7 \%$ falling into the $\$ 0-\$ 10,000$ category to $3 \%$ endorsing an income of $\$ 75,000-\$ 100,000$ per year.

Seventy-six percent of the mothers who completed questionnaires at Time 1 returned completed questionnaires one year later at Time 2. This smaller sample was made up of 42 boys and 14 girls who were still receiving services for identified developmental delays. Demographic characteristics of the participants in the current study are presented in Table 2 .

\section{Instruments}

\section{Attachment Measures}

The literature surrounding attachment theory describes two ways of conceptualizing the attachment construct. One way is categorical as was first described by Ainsworth and associates (1978) and Solomon and George (1999b). Assessment using these authors' understanding of attachment results in observed child behaviors falling into secure, insecure-avoidant, insecure-resistant, or insecure disorganized categories. In aligning with this conceptualization of attachment a categorical measure of attachment 
Table 2

Demographic Characteristics of Sample at Time 1

\begin{tabular}{|c|c|c|c|c|c|c|}
\hline \multirow[b]{2}{*}{ Demographic characteristics } & \multicolumn{2}{|c|}{$\begin{array}{l}\text { Original sample } \\
\quad \text { (Time 1) }\end{array}$} & \multicolumn{2}{|c|}{$\begin{array}{l}\text { Responders } \\
\text { (Time 2) }\end{array}$} & \multicolumn{2}{|c|}{$\begin{array}{l}\text { Nonresponders } \\
\text { (Time 2) }\end{array}$} \\
\hline & $n$ & $\%$ & $n$ & $\%$ & $n$ & $\%$ \\
\hline \multicolumn{7}{|l|}{ Gender of child } \\
\hline Male & 53 & 72 & 42 & 74 & 13 & 72 \\
\hline Female & 21 & 28 & 14 & 26 & 5 & 28 \\
\hline \multicolumn{7}{|l|}{ Ethnicity of child } \\
\hline Caucasian & 65 & 88 & 51 & 91 & 14 & 76 \\
\hline Hispanic & 9 & 12 & 5 & 9 & 4 & 24 \\
\hline \multicolumn{7}{|c|}{ Primary caregiver marital status (mother) } \\
\hline Married & 61 & 83 & 47 & 85 & 14 & 76 \\
\hline Single & 61 & 83 & 47 & 85 & 14 & 76 \\
\hline \multicolumn{7}{|l|}{ Number of siblings } \\
\hline 0 & 11 & 15 & 8 & 15 & 1 & 6 \\
\hline 1 & 25 & 34 & 23 & 41 & 4 & 22 \\
\hline $2-3$ & 27 & 36 & 18 & 31 & 10 & 56 \\
\hline $4-5$ & 11 & 15 & 7 & 13 & 3 & 16 \\
\hline \multicolumn{7}{|c|}{ Primary caregiver education (mother) } \\
\hline Below high school & 2 & 3 & 0 & - & 2 & 11 \\
\hline High school & 19 & 25 & 12 & 22 & 8 & 44 \\
\hline College & 30 & 42 & 24 & 43 & 6 & 33 \\
\hline BA/BS & 17 & 23 & 16 & 28 & 1 & 6 \\
\hline Grad/professional degree & 5 & 7 & 4 & 7 & 1 & 6 \\
\hline \multicolumn{7}{|l|}{ Father education } \\
\hline Below high school & 4 & 5 & 2 & 4 & 4 & 5 \\
\hline High school & 18 & 24 & 0 & - & 7 & 35 \\
\hline College & 26 & 35 & 12 & 22 & 8 & 30 \\
\hline $\mathrm{BA} / \mathrm{BS}$ & 21 & 28 & 19 & 37 & 4 & 20 \\
\hline Grad/professional degree & 5 & 7 & 3 & 6 & 1 & 19 \\
\hline \multicolumn{7}{|c|}{$\begin{array}{l}\text { Primary caregiver hours worked outside the } \\
\text { home per week }\end{array}$} \\
\hline 0 & 52 & 69 & 38 & 70 & 12 & 67 \\
\hline $3-10$ & 7 & 9 & 6 & 10 & 2 & 11 \\
\hline $11-30$ & 5 & 7 & 3 & 6 & 2 & 11 \\
\hline $31-40$ & 8 & 11 & 5 & 8 & 1 & 6 \\
\hline $41-50$ & 3 & 4 & 3 & 6 & 0 & 6 \\
\hline
\end{tabular}




\begin{tabular}{|c|c|c|c|c|c|c|}
\hline \multirow[b]{2}{*}{ Demographic characteristics } & \multicolumn{2}{|c|}{$\begin{array}{l}\text { Original sample } \\
\quad \text { (Time 1) }\end{array}$} & \multicolumn{2}{|c|}{$\begin{array}{l}\text { Responders } \\
\text { (Time 2) }\end{array}$} & \multicolumn{2}{|c|}{$\begin{array}{l}\text { Nonresponders } \\
\text { (Time 2) }\end{array}$} \\
\hline & $n$ & $\%$ & $n$ & $\%$ & $n$ & $\%$ \\
\hline \multicolumn{7}{|l|}{ Household income } \\
\hline$\$ 10,000$ or less & 5 & 7 & 4 & 8 & 1 & 6 \\
\hline$\$ 10,000-20,000$ & 8 & 11 & 4 & 8 & 2 & 11 \\
\hline$\$ 20,000-35,000$ & 13 & 18 & 12 & 19 & 3 & 17 \\
\hline$\$ 35,000-50,000$ & 32 & 43 & 22 & 41 & 11 & 61 \\
\hline$\$ 50,000-75,000$ & 14 & 19 & 12 & 19 & 1 & 6 \\
\hline$\$ 75,000-100,000$ & 2 & 3 & 2 & 5 & 0 & - \\
\hline \multicolumn{7}{|l|}{ Medical diagnosis } \\
\hline Premature/low birthweight & 13 & 18 & 7 & 18 & 4 & 22 \\
\hline Gestational diabetes & 2 & 3 & 1 & 2 & 1 & 6 \\
\hline Hydrocephalus & 2 & 3 & 0 & - & 2 & 11 \\
\hline FAE/FAS & 2 & 3 & 1 & & 0 & - \\
\hline Cystic fibrosis & 2 & 3 & & 4 & 0 & - \\
\hline Autism & 2 & 3 & 2 & 4 & 0 & - \\
\hline Cerebral palsy & 3 & 4 & 2 & 4 & 2 & 11 \\
\hline Down syndrome & 2 & 3 & 1 & 2 & 1 & 6 \\
\hline Seizure disorder & 2 & 1 & 1 & 2 & 0 & - \\
\hline Birth complications & 5 & 7 & 2 & 4 & 3 & 17 \\
\hline Other diagnosis & 11 & 15 & 2 & 4 & 3 & 17 \\
\hline No diagnosis & 28 & 38 & 8 & 14 & 2 & 11 \\
\hline \multicolumn{7}{|c|}{ Type of identified developmental delay } \\
\hline Global (2+ areas) & 38 & 51 & 26 & 46 & 12 & 67 \\
\hline Speech/language & 28 & 38 & 24 & 43 & 4 & 22 \\
\hline Visual & 2 & 3 & 2 & 4 & 1 & 6 \\
\hline Motor & 4 & 5 & 3 & 5 & 1 & 6 \\
\hline Social/emotional & 2 & 3 & 1 & 1 & 1 & 6 \\
\hline
\end{tabular}

was selected for use in this study. Due to the time and difficulty involved in conducting the Strange Situation (often considered the "gold standard" for assessment of attachment) and the intent to make this research replicable for use in other early intervention programs, the Strange Situation was not used as the categorical measure in this study. Instead, a measure adapted from the Strange Situation, the CAQ (Huggar, 1999), which delineates the same categories identified in the Strange Situation, was used (see Appendix D). The CAQ is a paper/pencil measure on which respondents are asked to 
indicate which group of behaviors best typifies/typified their child at the age of 18 months (see review of literature). Validity of this measure is based upon findings of Huggar and Curtis (1999), which indicated that children who scored in the clinical range for emotional problems on the Emotional Assessment for Infants, Toddlers, and Preschoolers (EAITP, Huggar, 1999) were more likely to exhibit insecure attachment behaviors as endorsed on the CAQ, $F(1,9)=19.02, p=.001$, This measure has not yet been validated with the Strange Situation.

The second way of conceptualizing attachment developed by Waters and Deane (1985) is to consider the security of attachment for each mother and her child to be somewhere upon a continuum from secure to insecure. Therefore, for this study a second measure of attachment, which measures attachment on a continuum, was also used. This second measure, which was shortened and adapted from the Attachment Q-Sort (Waters \& Deane, 1985) is the AQSQ developed by Robinson (1995) to provide a more efficient and useable measure in a clinical setting (see Appendix D). The measure includes the12 items, from the 90 item Attachment Q-Sort which Vaughn and Waters (1990) found to have the highest discrimination ability between secure and insecure attachment $(t$ values of 2.09-3.24, $p=.01-.005)$. It was designed to be used with children between the ages of one and four years. For this study, mothers of children with developmental delays rated these 12 items on a 9-point Likert scale. Each item was then compared to the score that was reported by identified experts to typify the "most securely attached" child. The Cronbach's alpha for this measure in the current sample was calculated at .70. This abbreviated measure (CAQ) has not been validated against the 90 item observer 
Attachment Q-Sort.

\section{Child Temperament Measure}

Since child temperament has been found to be related to degree of attachment security, a dimensional measure of temperament was used in this study. The Dimensions of Temperament Survey-Revised (DOTS-R, Lerner, Palermo, Spiro, \& Nesselroade, 1982) is considered a valid measure of temperament due to its basis on temperament dimensions outlined by Thomas and colleagues (1968) and its correlation with other measures of temperament (Windle, 1989). The child version of this measure, which test authors indicate is appropriate for children from birth through 12 years of age, was used in this study. Mothers of children with developmental delays completed this 54-item paper/pencil rating scale by indicating which behaviors were like and unlike their children. The results of the DOTS-R provided dimension scores in activity, attention, adaptability, rhythmicity and reactivity. The measure's summary temperament score, which indicates each child's score placement upon a continuum of scores from easy to difficult was used for analysis (see Appendix D). This measure was chosen due to its ease of utility and interpretation. The DOTS-R has been used in a large number of studies (e.g., Doelling \& Johnson, 1990; Weber et al., 1986; Windle \& Lerner, 1986) to assess the temperament of individuals from infancy to adulthood. Test-retest coefficients have been measured at .66 and concurrent validity studies have shown the correlation between DOTS-R temperament scores and a range of other temperament, mental health and competency measures (Windle, 1989, 1992). For the current sample, a Cronbach's alpha of .80 was found for the summary DOTS-R used in this study. 


\section{Child Behavior Problems Measure}

Problems behaviors of children in this study were assessed by maternal report,

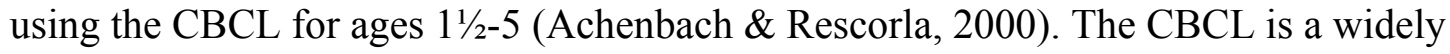
used 99-item measure that groups scores in tow overall domains (externalizing and internalizing behavior problems) and seven empirically based syndrome scales (emotional reactive, anxious/depressed, somatic complaints, withdrawn, sleep problems, attention problems, and aggressive behavior) as well as an overall score. The scores from the CBCL have shown good test-retest reliability on all scales $(r=.80-.90)$ and interparent agreement $(r=.61)$. Items on the CBCL have been found to discriminate significantly $(p<.01)$ between referred and non-referred children, and the instrument is correlated $(r=.46-.77)$ with other measures of behavior problems. The total behavior problem score on this measure was used for analysis. A Cronbach's alpha of .96 was calculated for the CBCL total score in the current study.

\section{Parent Stress Measure}

The PSI was used as a measure of the stress a mother feels in regard to the parentchild relationship. This measure is a paper/pencil questionnaire that allows parents to rate items regarding the difficulties and worries related to raising their child. It is designed to be used with parents of children from one month though 12 years of age. Researchers have found positive correlations between this measure and other measures of family competence and discord (Abidin, 1995). Adequate test-retest reliability (.82-.89) has been found for each of the three subscale scores (parental distress, parent-child dysfunctional interaction, and difficult child) as well as the overall parenting stress score. For the 
regression analysis in this study, the overall score of parenting stress was used. The Cronbach's alpha for total score in the current sample was found to be .94 .

\section{Maternal Psychological Problems Measure}

The Outcome Questionnaire-45.2 (OQ) was used to assess maternal psychological problems (see Appendix D). This 45-item paper/pencil instrument was developed to measure personally and socially relevant characteristics that affect the quality of life for an adult individuals 18 years and older (Lambert et al., 1996). It measures common symptoms for a wide range of adult mental health disorders and syndromes. It includes items which relate to three aspects of an individual's life (subjective discomfortintrapsychic functioning, interpersonal relationships, and social role performance. Cutoff scores have been derived which distinguish between a community sample and clinical samples. This measure has high internal consistency (.93) and test-retest reliability (.84). A Cronbach's alpha for the current study was calculated to be .95 . Moderate to high validity coefficients have been reported between the scale and other well-established measures of depression, anxiety, and global adjustment (Lambert et al., 1996). For this study, the overall OQ score was used in regression analysis to determine the contribution of maternal psychological functioning to the variance in attachment security.

\section{Social Desirable Response Measure}

The Marlowe-Crowne Social Desirability Scale (MC; Crowne \& Marlowe, 1960) was used to measure the degree to which mothers in the study tended to answer questions in socially accepted ways (see Appendix D). This measure was used to assess mothers' 
efforts to "fake good" in regard to their own stress and psychological problems or attempt to portray their children or their relationships with their children as more positive than they really are. The Marlowe-Crowne was found to be correlated with the L, F, and K validity scales of the MMPI ( $r=.54,-.36, .40$, respectively; Crowne \& Marlowe, 1960). The Cronbach's alpha for the MC in the current sample and was found to be .78 .

\section{Procedures}

Within the targeted early intervention program, each English-speaking family with a child identified as having a developmental delay that was between the ages of $1 \frac{1}{2}-2$ years was invited to participate in this study. A written explanation of the study and returnable note indicating interest in inclusion in the study were mailed to 182 mothers (see Appendix A). Subsequently a numbered packet including an informed consent document (see Appendix C), a demographic questionnaire (see Appendix A) and seven standardized measures (see Appendix D) were sent to each mother who had returned the signed note indicated they would like to be included in the study. Motivation for the return of measures was facilitated through a drawing for a number of cash prizes. Although 98 mothers initially indicated a desire to participate, only 74 packets of measures were returned for a response rate of $76 \%$. After receiving the measures, names were removed and secured in a locked file cabinet and numbers were used to identify data for analysis.

Using addresses provided by mothers who had completed the first series of questionnaires, a reminder letter (see Appendix B) was sent one year later letting parents 
know research packets would be arriving shortly. Four letters were returned and updated addresses were obtained for those mothers through contacts they had provided at Time 1. One week following the reminder letter, a second letter and packet of measures (the same measures completed at Time 1; see Appendix D) were sent to the 74 mothers who had completed the measures at Time 1. A second drawing for cash prizes, as well as a universal $\$ 5$ reward for the return of the measures was provided. Fifty-six completed packets of measures were returned (78\% response rate) for the follow-up assessment. Seventy-six percent of the mothers who completed questionnaires at Time 1 returned completed questionnaires 1 year later at Time 2. This smaller sample was made up of 42 boys and 14 girls who were still receiving services for identified developmental delays. Comparisons were made on all variables between those who responded at Time 2 and those who did not. There were no significant differences between responders and nonresponders. 


\section{CHAPTER IV}

\section{RESULTS}

\section{Descriptive Statistics and Preliminary Analyses}

Seven maternal report measures were used in this study. Three of these assess the maternal variables of psychological distress (OQ-45; Lambert et al., 1998), parenting stress (PSI; Abidin, 1995) and the tendency to respond in a socially desirable manner (MC; Crowne \& Marlowe, 1960). Two measures assess child characteristics: CBCL (Achenbach \& Rescorla, 2000) for behavior problems and the DOTS-R (Lerner, et.al, 1982) for temperament difficulties. The AQSQ (Robinson, 1995) was used measured the degree of attachment security, while the CAQ (Hugger, 1999) was used to identify attachment categories.

Descriptive analyses for Times 1, Time 1 comparison (the cases from Time 1 that were compared with Time 2 cases), and Time 2 are presented in Table 3. The data displayed includes means, ranges and standard deviations for all measures with the exception of the CAQ (which is a categorical measure).

To better understand the participants in this study, the percentage of those who scored above clinical cutoffs on the measures was calculated. These numbers are reported in Table 4. Authors of the OQ-45 (Lambert et al., 1996), PSI (Abidin, 1995), CBCL (Achenbach \& Rescorla, 2000) provide raw score cut-off scores for problems that are at a clinically significant level. A cut-off score for secure attachment on the AQSQ was also calculated by Robinson (1995). Although no cut-off scores were provided by 
Table 3

Descriptive Statistics for Measures

\begin{tabular}{|c|c|c|c|c|c|c|c|c|c|}
\hline \multirow[b]{2}{*}{ Measure } & \multicolumn{3}{|c|}{$\begin{array}{l}\text { Time } 1 \\
n=74\end{array}$} & \multicolumn{3}{|c|}{$\begin{array}{l}\text { Time } 1 \text { (Time } 2 \text { responders) } \\
\qquad n=56\end{array}$} & \multicolumn{3}{|c|}{$\begin{array}{l}\text { Time } 2 \\
n=56\end{array}$} \\
\hline & Mean & $S D$ & Range & Mean & $S D$ & Range & Mean & $S D$ & Range \\
\hline OQ-45 & 51.597 & 25.417 & $9-128$ & 49.833 & 23.985 & $9-128$ & 48.444 & 20.748 & $19-130$ \\
\hline PSI & 85.677 & 23.195 & $46-155$ & 84.981 & 22.782 & $46-155$ & 84.259 & 19.392 & $50-134$ \\
\hline $\mathrm{MC}$ & 18.629 & 5.486 & $1-29$ & 18.833 & 5.575 & $1-29$ & 18.259 & 5.486 & $4-27$ \\
\hline CBCL total score & 49.113 & 28.257 & $4-117$ & 48.389 & 28.271 & $4-117$ & 52.056 & 30.845 & $4-126$ \\
\hline CBCL internalizing & 14.343 & 11.396 & $0-53$ & 14.250 & 11.182 & $1-53$ & 15.130 & 10.120 & $2-47$ \\
\hline CBCL externalizing & 17.702 & 10.599 & $1-40$ & 17.274 & 9.723 & $3-36$ & 17.296 & 11.637 & $0-44$ \\
\hline DOTS-R & 141.581 & 17.019 & $101-192$ & 141.500 & 17.544 & $101-192$ & 143.590 & 19.211 & $103-234$ \\
\hline AQSQ & 46.090 & 10.402 & $18-90$ & 46.259 & 10.924 & $18-90$ & 45.667 & 9.405 & $20-65$ \\
\hline
\end{tabular}


Table 4

Percentages of Children in Each CAQ Attachment Category

\begin{tabular}{lccccc}
\hline Variable & $\begin{array}{c}\text { Clinical cut- } \\
\text { off score }\end{array}$ & $\begin{array}{c}\text { One SD above } \\
\text { community } \\
\text { sample average }\end{array}$ & $\begin{array}{c}\text { Time 1 } \\
n=74 \\
\% \text { above }\end{array}$ & $\begin{array}{c}\text { Time 1 (Time 2 } \\
\text { responders } n= \\
56 \% \text { above }\end{array}$ & $\begin{array}{c}\text { Time 2 } \\
n=56 \\
\% \text { above }\end{array}$ \\
\hline OQ-45 & 63 & & 22.6 & 25.4 & 18.5 \\
PSI & 90 & & 60 & 58.8 & 42.8 \\
CBCL total score & 59 & & 41.9 & 46.3 & 40.3 \\
CBCL internalizing & 18 & & 27.4 & 26.9 & 33.3 \\
CBCL externalizing & 24 & & 27.8 & 35.8 & 27.8 \\
MC & & 19.5 & 50 & 46.3 & 38.9 \\
DOTS_R & 145 & 47.5 & 46.2 & 44.4 \\
& & & \% below & $\%$ below & $\%$ below \\
& & & (insecure) & (insecure) & (insecure) \\
AQSQ & 7,250 & & 65.8 & 64.9 & 56.7 \\
\hline
\end{tabular}

authors of the DOTS-R (Lerner et al., 1982) and MC (Crowne \& Marlowe, 1960), community population average scores and standard deviations were given. Scores that were one standard deviation above the community population average score were calculated and reported.

Relationships between attachment, parent and child variables, and subsequent behavior problems were examined for this sample of children with developmental delays correlations between variables and are presented in Table 5.

\section{Attachment in Children with Developmental Delays}

The first research question addressed in this study was to identify the percentage of children with developmental delays who fall into each area of attachment using both a categorical system (secure, avoidant, resistant and disorganized) as measured by the CAQ 
Table 5

Correlations Between Attachment, Time 1 Variables, and Time 2 Behavior Problems

\begin{tabular}{lcccccccc}
\hline \multicolumn{1}{c}{ Variables } & Time 1 & CAQ & Time 1 & Time 1 & Time 1 & Time 1 & Time 1 & Time 2 \\
CBCL & Time 2 \\
PSI & MC & DOTS & INT & EXT. \\
\hline Time 1 & .241 & - & & & & & & \\
AQSQ & .061 & & & & & & & \\
Time 1 & .011 & .166 & - & & & & & \\
OQ & .521 & .016 & & & & & & \\
Time 1 & -.024 & -.279 & .743 & - & & & & \\
PSI & .202 & .000 & .000 & & & & & \\
Time 1 & -.065 & -.082 & -.380 & -.384 & - & & &. \\
MC & .257 & .742 & .002 & .002 & & & & \\
Time 1 & -.066 & -.472 & .165 & .332 & .016 & - & & \\
DOTS & .003 & .000 & .199 & .008 & .903 & & & \\
Time 2 & -.278 & -.380 & .120 & .344 & .138 & .523 & - & \\
CBCL INT & .028 & .003 & .388 & .011 & .319 & .000 & & \\
Time 2 & -.376 & -.329 & .090 & .290 & .189 & .375 & .712 & - \\
CBCL EXT & .003 & .008 & .518 & .34 & .223 & .005 & .000 & \\
Time 2 & -.351 & -.379 & .096 & .334 & .148 & .500 & .906 & .921 \\
CBCL TOT & .005 & .003 & .489 & .014 & .288 & .000 & .000 & .000 \\
\hline
\end{tabular}

Note. Top number $=$ Pearson $r$ correlation, bottom number $=p$ value significance.

and a continuum of attachment (i.e., degree of security) as measured by the AQSQ (see Table 6). All of the children in this sample with identifiable developmental delays at two years of age, regardless of type of delay, were grouped together for this analysis. Time 1 data only were used for these analyses.

As reported in Table 6, based on results from the CAQ, $60.8 \%$ of the children with developmental delays fell in the securely attached category. This is similar to the $59 \%$ and $62 \%$ secure that has been reported for typically developing children (Andreozzi, Flanagan, Seifer, Brunner, \& Lester, 2002; Crittenden, 1988). In the insecure categories, however, differences are noted between percentages reported by Crittenden (1988) and 
Table 6

Percentages of Children in Each CAQ Attachment Category

\begin{tabular}{cccccc}
\hline Measure & $N$ & Secure & Insecure - resistant & Insecure - avoidant & Insecure - disorganized \\
\hline CAQ Time 1 & 74 & $\begin{array}{c}60.8 \% \\
(n=45)\end{array}$ & $\begin{array}{c}31.1 \% \\
(n=23)\end{array}$ & $\begin{array}{c}2.7 \% \\
(n=2)\end{array}$ & $\begin{array}{c}5.4 \% \\
(n=4)\end{array}$ \\
\hline
\end{tabular}

Andreozzi and colleagues (2002) and the resulting percentages in this study. While Crittenden (1988) reported 5\% of children fell in the resistant category and Andreozzi and associates (2002) reported $11.8 \%$ of children fell into this category, mothers in the current study identified $31.1 \%$ of their children as resistant. Likewise for the avoidant category differences were found. In samples of typically developing children, $30 \%$ (Crittenden, 1988) and 12\% (Andreozzi et al., 2002) of the children fell into the avoidant range. This is compared to just $2.7 \%$ of the children with developmental delays identified by their mothers as avoidant. Lastly, 5\% (Crittenden, 1988) to 19\% (Andreozzi et al., 2002) of typically developing children are found to show behaviors of disorganized attachment while $5.4 \%$ of the children with developmental delays fell into the disorganized attachment category.

A second analysis was then conducted by combining children falling into the avoidant, resistant, and disorganized attachment categories into one insecure category. The results of this analysis are reported in Table 7.

Based on this analysis, similar percentages of children with developmental delays were identified as being securely and insecurely attached as children who are typically developing, as reported in the literature (Andreozzi et al., 2002; Crittenden, 1988). 
Table 7

Percentages of Children in CAQ Secure-Insecure Attachment Categories

\begin{tabular}{lccc}
\hline Measure & $\mathrm{N}$ & Secure & Insecure \\
\hline CAQ Time 1 & 74 & $60.8 \%$ & $39.2 \%$ \\
& & $(n=45)$ & $(n=39)$ \\
\hline
\end{tabular}

When examining the results from the AQSQ, the Lay, Waters, Posada and Ridgeway's (1995) method of calculating security scores was utilized. In their method each subject's scores were compared (via a Pearson $r$ correlation) with expert ratings of the hypothesized most securely attached child (Waters, 1997) resulting in a correlation coefficient security score for each subject. These scores were then compiled to produce a mean security score for the group. The mean security score for typically developing children was reported to be $.32(S D=.16)$ in a meta-analysis of Attachment Q-Sort studies (Van Ijzendoorn, Vereijken, Bakermans-Kranenburg \& Riksen-Walraven, 2004).

A similar process was used to determine the mean security AQSQ score within this study's sample of children with developmental delays. Since the items in the AQSQ are a subsample of those used in the Attachment Q sort, the expert's hypothesized most securely attached child score for each item (Lay et al., 1995) was used to determine a hypothesized most securely attached child using the AQSQ. The mean security score (correlation) was $.28(S D=.29)$ for children with developmental delays.

\section{Parent Factors that Predict Security}

The second research question was designed to examine the degree to which parent 
factors and child factors predicted attachment security for children with developmental delays. It was hypothesized that the parent factors of parenting stress (as measured by the PSI), psychological problems (as measured by the OQ-45), as well as the degree of social desirable responses (as measured by the MC) would contribute to the variance in attachment security. Stepwise multiple regression analysis was used to predict scores on the AQSQ while binary logistic regression was used to predict security or insecurity as measured by the CAQ. The overall regression, using the Time 1 AQSQ scores as the dependent variable, resulted in a significant overall model, $\mathrm{F}(3,71)=5.000, p=.003$, $\left.R^{2}=.174\right)$. In looking at the specific variables that significantly contributed to this model (see Table 8), greater parenting stress (PSI) predicted a lower degree of attachment security, while greater maternal psychological problems (OQ-45) were predictive of a higher degree of security. Social desirability of responses (MC) was not a significant predictor of attachment security as measured by the AQSQ.

A logistic regression analysis was performed with attachment security as measured by the CAQ as the dependent variable and maternal psychological problems (OQ), parenting stress (PSI) and degree of social acceptable answers (MC) as predictor

Table 8

Contribution of Parent Factors to the Degree of Attachment Security (AQSQ)

\begin{tabular}{lccccccc}
\hline & \multicolumn{2}{l}{ Unstandardized coefficients } & & \multicolumn{2}{l}{ Standardized coefficients } & & \\
\cline { 2 - 3 } Variable & $\mathrm{B}$ & Std. Error & & Beta & & \multicolumn{1}{c}{ Sig. } \\
\hline OQ-Time 1 & .166 & .067 & & .394 & & 2.467 & .016 \\
PSI-Time 1 & -.279 & .072 & & -.605 & & -3.865 & .000 \\
MC-Time 1 & -.082 & .230 & & -.042 & & -.358 & .742 \\
\hline Note. Dependent variable Time 1 AQSQ & & & &
\end{tabular}


variables. Seventy-four cases were analyzed. Although the full model did not predict attachment security (Omnibus chi-square $=3.646, d f=3, p=.302$ ), it accounted for between $4.8 \%$ and $6.5 \%$ of the variance in security status. A total of $97.4 \%$ of the children with secure attachments were successfully predicted, while only $9.1 \%$ of the children with insecure attachments were predicted. Overall, $65.6 \%$ of the predictions were accurate. Table 9 gives coefficients and the Wald statistic with associated degrees of freedom and probability values for each of the predictor variables. These results show that none of the parent factors used significantly predicted secure attachment (at a statistically significant level) as measured by the CAQ.

\section{Child Factors that Predict Attachment Security}

The contribution of child factors to attachment was also evaluated via regression analyses. It was hypothesized that both child gender and child temperament would be significant predictors of attachment security in children with developmental delays. This regression using the AQSQ continuum measure of attachment security at Time 1 as the dependent variable resulted in a significant overall model, $F(2,71)=11.514, p=.000$, $\left.R^{2}=.245\right)$. In looking at the contributions of the individual predictors, greater child

Table 9

Contribution of Parent Factors to Secure Attachment (CAQ)

\begin{tabular}{llccccr}
\hline Variable & $B$ & SE & Wald & $d f$ & Sig. & $\operatorname{Exp(B)}$ \\
\hline OQ-Time1 & .011 & .017 & .412 & 1 & .521 & 1.011 \\
PSI-Time 1 & -.024 & .018 & 1.626 & 1 & .202 & .977 \\
MC- Time 1 & -.065 & .057 & 1.287 & 1 & .257 & .937 \\
Constant & 3.349 & 1.873 & 3.198 & 1 & .074 & 28.476 \\
\hline Note. Dependent variable CAQ Time 1. & & & &
\end{tabular}


temperament difficulties were associated with lower attachment security. Gender was not predictive of attachment security (see Table 10).

Using the dependent variable of secure attachment measured by the CAQ at Time1 and sex and temperament (DOTS-R) of the child as predictor variables, a logistic regression analysis was conducted. The full model in this analysis significantly predicted secure attachment (omnibus chi-square $=16.608, d f=2, p<.0005$ ) and accounted for between $20.6 \%$ and $28.1 \%$ of the variance in attachment security status. The analysis also showed that $84.4 \%$ of the children with secure attachments were predicted by these variables, while $44.4 \%$ of the children in the insecure attachment category were predicted. Table 11 reports the coefficients, Wald statistic, degrees of freedom and probability values for the predictor variables of sex and temperament. It shows that temperament (but not sex) is a significant predictor of secure attachment as measured by the CAQ.

\section{Stability of Attachment Security Scores for One Year's Time}

The third research question addressed in this study was designed to determine the stability of attachment scores (as measured by both the CAQ and AQSQ attachment

Table 10

Contribution of Child Factors to Degree of Attachment Security (AQSQ)

\begin{tabular}{|c|c|c|c|c|c|}
\hline \multirow[b]{2}{*}{ Variable } & \multicolumn{2}{|c|}{ Unstandardized coefficients } & \multirow{2}{*}{$\begin{array}{c}\text { Standardized coefficients } \\
\text { Beta } \\
\end{array}$} & \multirow[b]{2}{*}{$t$} & \multirow[b]{2}{*}{ Sig. } \\
\hline & $B$ & Std. Error & & & \\
\hline Sex Time 1 & -.784 & 2.405 & -.034 & -.326 & .745 \\
\hline DOTS-R Time 1 & -.318 & .067 & -.492 & -4.768 & .000 \\
\hline
\end{tabular}


Table 11

Contribution of Child Factors to Secure Attachment (CAQ)

\begin{tabular}{lcccccr}
\hline Variable & $B$ & SE & Wald & $d f$ & Sig. & \multicolumn{1}{c}{$\operatorname{Exp(B)}$} \\
\hline DOTS-R & -.066 & .022 & 9.130 & 1 & .003 & .936 \\
SEX & .413 & .693 & .355 & 1 & .551 & 1.511 \\
Constant & 9.800 & 3.167 & 9.573 & 1 & .002 & 18026.287 \\
\hline Note. Dependent variable Time 1 CAQ. & & & &
\end{tabular}

measures) over time. For the AQSQ, Pearson $r$ correlations between Time1 and Time 2 scores were calculated. There was a significant correlation between scores $(r=.571$, $p=.000$ ) indicating stability of attachment security over time. Likewise, for the CAQ (using the secure/insecure only categories) a correlation of $r=.433(p=.000)$ was obtained.

To obtain more specific information on changes over time, the movement between the general categories of secure and insecure attachment on the CAQ was examined. Table 12 describes the number of children who remained categorized in the same way, and those whose measured security changed between Time 1 and Time 2. A McNemar chi-square calculation indicated that security of attachment did not change significantly over one year's time.

\section{Prediction of Behavior Problems}

The final research question examined in this study was the degree to which scores of attachment security at age $1 \frac{1}{2}$ to 2 years predicted behavior problems one year later in this sample of children. The CBCL was used to measure behavior problems and the internalizing, externalizing, and total raw score was used for these analyses. Stepwise 
multiple regressions with CAQ scores (secure and insecure) and AQSQ total scores were used to predict behavior problems using maternal report attachment scores at Time 1. This regression resulted in significant overall models for all three of these variables (Internalizing: $F(2,51)=9.566, p=.000, R^{2}=.273$; Externalizing: $F(2,51)=11.413$, $p=.000, R^{2}=.309$; Total: $\left.F(2,50)=12.472, p=.000, R^{2}=.333\right)$. Attachment, as measured by both the CAQ and the AQSQ were significant predictors of behavior problems, both internalizing and externalizing, at Time 2 with less secure attachment being associated with a higher level of behavior problems (see Tables 13, 14, and 15).

Table 12

Changes in Attachment Security (CAQ) Over 1 Year's Time

\begin{tabular}{lcc}
\hline Variable & Secure Time 2 & Insecure Time 2 \\
\hline Secure Time 1 & $48 \%$ & $18 \%$ \\
& $(n=27)$ & $(n=10)$ \\
Insecure Time 1 & $9 \%$ & $25 \%$ \\
& $(n=5)$ & $(n=14)$ \\
\hline
\end{tabular}

Table 13

Attachment Scores (Time 1) Prediction of Internalizing Behavior Problems (Time 2)

\begin{tabular}{|c|c|c|c|c|c|}
\hline \multirow[b]{2}{*}{ Variable } & \multicolumn{2}{|c|}{ Unstandardized coefficients } & \multirow{2}{*}{$\frac{\text { Standardized coefficients }}{\text { Beta }}$} & \multirow[b]{2}{*}{$t$} & \multirow[b]{2}{*}{ Sig } \\
\hline & $B$ & Std. Error & & & \\
\hline Constant & 35.212 & 5.272 & & 6.679 & .000 \\
\hline CAQ-secure Time 1 & -5.844 & 2.582 & -.278 & -2.263 & .028 \\
\hline AQSQ- Time 1 & -.352 & .114 & -.380 & -3.091 & .003 \\
\hline
\end{tabular}

Note. Dependent variable CBCL-Internalizing-Time 2 raw score. 
Table 14

Attachment Scores (Time 1) Prediction of Externalizing Behavior Problems (Time 2)

\begin{tabular}{lccccccc}
\hline & \multicolumn{2}{l}{ Unstandardized coefficients } & & \multicolumn{2}{c}{ Standardized coefficients } & & \\
\cline { 2 - 3 } Variable & $B$ & Std. Error & & Beta & & Sig. \\
\hline Constant & 39.388 & 5.908 & & & 6.667 & .000 \\
CAQ-secure Time 1 & -9.089 & 2.894 & & -.376 & -3.141 & .003 \\
AQSQ- Time 1 & -.350 & .128 & & -.329 & -2.742 & .008 \\
\hline
\end{tabular}

Note. Dependent variable CBCL-Externalizing-Time 2 raw score.

Table 15

Attachment Scores (Time 1) Prediction of Behavior Problems (Time 2)

\begin{tabular}{|c|c|c|c|c|c|}
\hline \multirow[b]{2}{*}{ Variable } & \multicolumn{2}{|c|}{ Unstandardized coefficients } & \multirow{2}{*}{$\frac{\text { Standardized coefficients }}{\text { Beta }}$} & \multirow[b]{2}{*}{$t$} & \multirow[b]{2}{*}{ Sig. } \\
\hline & $B$ & Std. Error & & & \\
\hline Constant & 116.572 & 15.548 & & 7.497 & .000 \\
\hline CAQ-secure Time 1 & -22.867 & 7.759 & -.351 & -2.947 & .005 \\
\hline AQSQ- Time 1 & -1.071 & .336 & -.379 & -3.184 & .003 \\
\hline
\end{tabular}

Note. Dependent variable CBCL-Time 2 total raw score. 


\section{CHAPTER V \\ DISCUSSION}

Secure mother-child attachment has been found to be a strong predictor of prosocial behaviors in children who are typically developing, while insecure attachment predicts behavior problems (Oppenheim et al., 1999; Sroufe et al., 2000). Until recently, there has been a paucity of information available about mother-child attachment in children with developmental delays. Research on attachment in these children is necessary in order to better understand the family context of children with developmental delays and to provide early intervention services that will result in successful life outcomes. The findings from this study provide information about security of attachment in children with developmental delays including predictors of attachment, changes over time, and the relationship between attachment and behavior problems.

\section{Security of Attachment in Children with Developmental Delays}

As predicted, the findings from this study indicate that the categorization of secure attachment (60.8\% using CAQ) in children with developmental delays is similar in percentage to that of children who are typically developing as measured by the Strange Situation (62\%-Andreozzi et al., 2002; 59\% — Crittenden, 1988). It would follow then, that the overall percentage of insecurely attached children (avoidant, resistant, and disorganized taken together) is similar to the percentage obtained within samples of children who are typically developing. Interesting differences occurred, however, in the percentages of children with developmental delays who fell into the avoidant and 
resistant categories of insecure attachment. While studies of attachment in samples of children who are typically developing resulted in $30 \%$ of the children falling into the avoidant range of insecure attachment, only $2.7 \%$ of the children with developmental delays fell into the avoidant category (Andreozzi et al., 2002; Crittenden, 1988). The descriptor for the avoidant category on the CAQ, which was adapted from observed behaviors in the Strange Situation follows.

My child tends to explore a new environment outside the home, without interaction with me. When I return after being away from him/her, my child avoids or ignores me.

Generally, my child interacts with me and strangers in a similar manner. My child tends to cry more when left alone than with a stranger.

It seems there may be several possible contributors to the lower percentage of children with developmental delays falling into this category. The first may simply be the inability of some children with delays to physically explore new environments independently. Since $5 \%$ of the children in this sample were identified as having motor delays exclusively and 51\% had global delays that included motor impairments, this may at least partially explain the difference. A second factor may be the higher incidence of medical procedures undergone by children in this sample. Sixty-two percent of these children have received medical diagnoses, which in some cases involve intrusive and/or painful tests. This could contribute to a child's reluctance to explore a new environment without his/her mother as well as being more upset in the presence of a stranger than being left alone. Differences between the child's interaction with his/her mother and a stranger would likely also be impacted. Since many children with developmental delays require or demand more frequent and/or more intense care by caregivers, it is possible that the 
opportunities for exploring new environments are fewer as well.

Although the percentage of children with developmental delays who fell into the insecure disorganized category was similar to the percentage for children who are typically developing, the difference in the insecure resistant category was also notable. While the percentage of children who are typically developing and identified as insecure resistant was 5\% (Crittenden, 1988) and 11.8\% (Andreozzi et al., 2002) in two studies using the Strange Situation, $31.5 \%$ of the mothers in the current study identified their child's behaviors as insecure resistant. Again, an examination of the CAQ item for insecure resistant category lends insight into possible explanations for the differences between population samples. The description from the CAQ follows.

My child tends to be upset by an unfamiliar room or adult even when I am present.

In a new environment outside the home, my child tends to not explore this new room and becomes very upset if I leave the room. When I return, after being away from my child, he/she is difficult to comfort and often shows anger.

Once again, the increased likelihood of separation and intrusive/painful medical procedures for children with developmental delays may explain the increased endorsement of this item. This difference has been observed in some studies of attachment in children with medical problems early in life (Maris, Endriga, Speltz, Jones, \& DeKlyen, 2000).

The results from the AQSQ indicate that the children with developmental delays in this sample obtained a slightly lower degree of attachment security than children who are typically developing. These findings support previous studies that found lower attachment security in samples of children with various medical or developmental 
problems (Cassibba, Van IJzendoorn, Bruno, \& Cuppola, 2004; Maris et al., 2000; Moran, Pederson, Pettit., \& Krupka, 1992; Vaughn \& Bost, 1999).

\section{Maternal Predictors of Attachment}

To further explore contributing factors to the categorization or degree of secure attachment in children with developmental delays, three maternal characteristics were evaluated in relation to attachment. Parenting stress, maternal psychological problems and a mother's tendency to respond in socially acceptable ways were posited as possible predictors of attachment security. It was found that greater reported stress in parenting a child with a developmental delay (as measured by the PSI) was related to poorer attachment security as measured by the AQSQ. Although parenting stress was not predictive of attachment security as measured by the CAQ, the results using the AQSQ suggest that providing interventions to decrease maternal parenting stress may be beneficial in increasing the degree of secure attachment for children with developmental delays.

Maternal psychological problems as measured by the OQ-45 were weakly associated with higher attachment security scores on the AQSQ. Characteristics of the population used in this study may lend a plausible explanation for these findings. It is possible that because the study was conducted in an area of Utah with a high percentage of the population who are members of The Church of Jesus Christ of Latter-day Saints (Mormon), the reporting of psychological problems would be affected. Members of this faith are known to value families, children, and motherhood, and provide a strong support 
system to their members. Support can include financial resources, mental health treatment, spiritual understanding and a sense of belongingness, in addition to physical assistance with the everyday concerns of child care. Therefore, it is plausible that psychological problems of the mothers or the developmental delay of the child in this sample could actually increase the help she receives. Since the presence of a social support in a mother's life has been shown to be related to the attachment security of her child (Jacobsen \& Frye, 1991), this may explain the increased the association between maternal psychological problems and attachment security in this sample of children with developmental delays. Additional research with children with developmental delays with mothers with and without psychological problems in a similar population would be required to support this hypothesis.

Mothers' tendency to respond in socially appropriate ways (as measured by the MC) was not predictive attachment security (AQSQ and CAQ) in this study. This may again be related to the degree of conservative religious beliefs in this population.

Regardless, in this case, these results lend strength to the study, since socially desirable responses need not be considered a factor in the prediction of attachment.

\section{Child Predictors of Attachment}

Two characteristics of the child were explored to determine their contribution to the security of attachment. The child's gender and the child's temperament (as measured by the DOTS-R) were used in a regression analysis to predict attachment scores.

Although gender has been found to be a predictor of temperament (Else-Quest, Hyde, 
Goldsmith, \& Van Hulle, 2006), this study supports previous studies of attachment in children who are typically developing (Colin, 1996) as the child's gender was not related to the security of attachment.

Child temperament did predict attachment security in this sample of children with developmental delays. Children with characteristics of a more difficult temperament were less securely attached. This is consistent with previous literature that indicates that difficulty of temperament predicts poorer attachment security in children who are typically developing (Moran et al., 1992). This relationship seems logical. Because a child with a difficult temperament has a higher activity level, a more negative mood, withdraws more readily, is more rigid in thinking, more distractible and does not adhere to a predictable schedule, it follows that these characteristics make it more difficult to form a secure attachment. This seems true for both the mother and the child. From the child's perspective, a mother would not be able to meet the child's needs, which are much different than those of a child with an "easy" temperament. This could be exacerbated by health problems and separations due to medical procedures. On the other hand, a mother would have difficulty feeling warm, loving and attached feelings toward a child who was difficult to calm or predict behaviorally. Thus the results of this analysis were consistent with the findings for previously studied populations, which indicate that the temperament of the child does contribute to the degree of attachment security. In this study, as in previous studies, the more difficult the temperament, the less secure the attachment. 


\section{Stability of Attachment in Children with Developmental Delays}

Statistical analysis of attachment security scores on both the AQSQ and CAQ measures answered the third research question concerning the stability of attachment in children with developmental delays. The analysis indicated that over one year's time, there was not a statistically significant change in attachment security for this sample. This finding may lend support for the reliability of these measures. The changes that did occur may be influenced by the developing independence of the children at the time of the second measurement, or medical intervention which can interrupt attachment at either an earlier or later age.

\section{Attachment as a Predictor of Behavior Problems in Children with Developmental Delays}

A final question answered by this study concerned whether attachment security could predict the severity of behavior problems in children with developmental delays over time. The results indicate that poorer attachment security at ages $1 \frac{1}{2}-2$ years did predict behavior problems at ages $2 \frac{1}{2}-3$ years in this sample of children with developmental delays. Since this relationship has been shown previously in studies of children who are typically developing (Greenberg, 1999; Van IJzendoorn et al., 1999), this study suggests that although there are differences in a number of important areas of development between these two groups of children, attachment security is predictive of behavior problems in both populations. 


\section{Limitations and Future Directions}

There are a number of limitations of this study, and the use and generalization of the findings herewith should be considered given these limitations. One obvious issue in the study is the small number of cases available for study. One hundred eighty-six invitations for participation were distributed and 98 mothers returned signed forms indicating desire to be included. Of the 98 packets of questionnaires which were sent out, $74(68 \%)$ were returned completed. Although of interest, no data were available to compare the differences between those who completed the measures and those who did not. Additional attrition occurred from the first completion of measures (Time 1) and the return of follow-up measures at Time 2. Feedback from two mothers indicated their opinions that the packet of assessment materials was difficult to complete due to the length and number of measures. This may have contributed to the attrition rate of $24 \%$ between Time 1 and Time 2 . It is recognized that those individuals who originally chose not to participate, and/or those who failed to return completed questionnaires may be reflective of a systematic bias in this study. It is possible that mothers who competed Time 2 questionnaires may have a higher interest in the development of their child.

The participants in this study reflect a convenience sample taken from one Early Intervention program in northern Utah and thus cannot represent other Early Intervention programs within or outside of the state of Utah. Furthermore, due to the small sample size, all areas of developmental delay (cognitive, language, vision, hearing, motor, and social/emotional) were collapsed into one category of developmental delay. With a higher number of participants, analyses using each of these categories may show unique factors 
(e.g., ability to express emotion, communicate, and seek proximity) that influence the development of attachment security.

Other limitations of the study may have to do with the measures used. Although the OQ-45 is a well accepted measure of psychological problems in adults, and maternal psychological problems have been found to predict attachment security in children who are typically developing, analysis in this study did not indicate the same relationship. Possible problems with the measure may be due to specific differences of this population in northern Utah, the unique characteristics of mothers of children with developmental delays, or the OQ-45's primary use as a therapy outcome measure.

A unique feature and possible limitation of this study was the use of paper-pencil measures of attachment. The biggest weakness concerns the lack of psychometric information available for the measures. Nonetheless it is important to remember that one of the salient goals of this study was to make it replicable for other Early Intervention programs. Although the Strange Situation is considered the best measure of categories of attachment, it requires specific training and personnel to conduct this assessment. In addition it requires a room in which to conduct each step of the assessment protocol, along with a method of observation and/or videotaping the behaviors of the child in response to separations from the mother, which are often distressing to the child. The training, personnel, resources and time required for the implementation of this measure of attachment is not feasible in typical Early Intervention programs. Therefore a measure which describes behaviors from each attachment category which might be observed in a Strange Situation (CAQ) was used in the study. The CAQ, which described child 
behaviors that are typically seen for each attachment category in the Strange Situation, required the mothers to choose one group of behaviors that typified her child. For efficiency, only a limited number of behaviors are described, which makes selection of one category difficult. Some mothers added comments that none of the groups of behaviors were completely descriptive of their children, and they were uncomfortable choosing only one category. Regardless, the mothers' categorization of secure and insecure attachment was found to be stable over one year's time, with a low percentage of children moving from secure to insecure or insecure to secure categories.

The other most popular measure of attachment, the 90 item Attachment Q-Sort, also requires additional training, personnel, and time, which are not available to most Early Intervention programs. The AQSQ, which was comprised of a subsample of the items used in the Attachment Q-sort, was not directly supported by the Attachment Q-sort authors. Although variations of the Attachment Q-sort have been used in the past, recent research comparing scores from the adapted measures and those of the Attachment Q-sort suggests the use of the observer Attachment Q-sort (which requires 6 or more hours of trained observer time) is the most highly correlated with the Strange Situation secure attachment scores (Tarabulsy et al., 1997; Teti \& McGourty, 1996). Although other validity data were presented by the authors of the AQSQ, direct analyses between the paper-pencil AQSQ scores and observer Attachment Q-sort scores are not yet available. However, in this study the AQSQ showed stability of attachment scores $(r=.571$, $p=.000$ ) over one year's time. These results suggest reliability of this measure and add to the evidence that the security of attachment remains moderately stable in children with 
developmental delays in early childhood.

Future research is needed to better determine the validity and reliability of both the CAQ and the AQSQ as measures of attachment. Administering these measures along with the Strange Situation and/or the Observer Attachment Q-Sort would help determine their effectiveness as screening measures of attachment. It will also be necessary to evaluate the reliability and utility of these paper-pencil measures in Early Intervention programs.

Another conundrum posed by this study involved the use of the attachment measures both at ages $1 \frac{1}{2}-2$ years of age and again at $2 \frac{1}{2}-3$ years of age. Previous research has suggested that attachment behaviors in younger children differ from those of older children. Studies using the Strange Situation are with children between the ages of 9 and 18 months and the Attachment Q Sort has not been studied in children older than 3 years of age. Other measures, which assess the somewhat different attachment behaviors of older children, have been developed to assess attachment in children who are preschool and kindergarten ages. Since the children followed in this study were older (at Time 2) than children studied in the Strange Situation, and at the upper age limit of the Attachment Q sort, the use of the same measures of attachment for both Time 1 and Time 2 may be questioned. Establishing the stability of attachment using the same measures for both infants and older children may not be sensitive to the differences of attachment behaviors in the older children. However, using scores from different measures of attachment, one designed for infants (as in Time 1) and one for older attachment behaviors (as in Time 2), would likely not be analogous. 
This study was exploratory in nature, and it will be necessary to verify the results with additional research of attachment in children with developmental delays. It is suggested that future studies utilize other early intervention programs throughout the country due to the need to tie research to services for these children. Including large numbers of children would make it possible to consider different areas of developmental delay separately, which could add important information to the literature. 


\section{REFERENCES}

Abidin, R. (1995). Parenting Stress Index: Professional manual ( $3^{\text {rd }}$ ed.). Odessa, FL: Psychology Assessment Resource.

Abrams, K.Y. (2001). Pathways to disorganization: A study concerning varying types of parental frightened and frightening behaviors as related to disorganized attachment (Doctoral dissertation). University of California, Berkley, CA.

Achenbach, T M. (1992). Manual for the Child Behavior Checklist 2-3 and 1992 profile. Burlington, VT: University of Vermont, Department of Psychiatry.

Achenbach, T.M., \& Rescorla, L. (2000). Manual for the ASEBA preschool forms and profiles. Burlington VT: University of Vermont, Department of Psychiatry.

Ainsworth, M.D. (1985). Patterns of attachment. Clinical Psychologist, 38(2), 27-29.

Ainsworth, M.D., Blehar, M., Waters, E., \& Wall, S. (1978). Patterns of attachment: A psychological study of the Strange Situation. Hillsdale, NJ: Erlbaum.

Al-Yogon, M. (2003). Children at risk for learning disorder: Multiple perspectives. Learning Disabilities Research and Practice, 36(4), 12-20.

Andreozzi, L., Flanagan, P., Seifer, R., Brunner, S., \& Lester, B. (2002). Attachment classifications among 18-month-old children of adolescent mothers. Archives of Pediatric Adolescent Medicine, 156(2), 20-26.

Antshel, K., Stallone, K., AbdulSabur, N., Shprintzen, R., Roizen, N., Higgins, A., \& Kates, W. (2007). Temperament in velocardiofacial syndrome. Journal of Intellectual Disability Research, 51(3), 218-227.

Arhin, A. (2006). Effect of bug-in-the-ear-feedback as an intervention to promote attachment behaviors in the adolescent mother infant dyad (Doctoral dissertation). University of Florida, Gainesville, FL.

Atkinson, L., Chisholm, V.C., Scott, B., Goldberg, S., Vaughn, B.E., Blackwell, J., ..., Tam, F. (1999). Maternal sensitivity, child functional level, and attachment in Down syndrome. Monographs of the Society for Research in Child Development, 64(3), 45-66.

Atkinson, L., Paglia, A., Coolbear, J., Niccols, A., Parker, K.C., \& Guger, S. (2000). Attachment security: A meta-analysis of maternal mental health correlates. Clinical Psychology Review, 20(8), 1019-1040. 
Atkinson, L., \& Zucker, K.J. (Eds.). (1997). Attachment and psychopathology. New York, NY: Guilford.

Baird, S.M., Haas, L., McCormick, K., Carruta, C., \& Turner, K.D. (1992). Approaching an objective system for the observation and measurement: Infant-parent social interaction code. Topics in Early Childhood Special Education, 12(4), 544-571.

Balbernie, R. (2010). Reactive attachment disorder as an evolutionary adaptation. Attachment and Human Development, 12(3), 265-281.

Barden, R.C., Ford, M.E., Jensen, A.G., Rogers-Slayer, M., \& Slayer, K.E. (1989). Effects of craniofacial deformity in infancy on the quality of mother-infant interactions. Child Development, 60(4), 819-824.

Bartholomew, K., \& Horowitz, L.M. (1999). Attachment styles among young adults: A test of the four-category model. Journal of Personality and Social Psychology, 61(2), 226-244.

Bauminger, N., \& Kimhi-Kind, I. (2008). Social information processing, security of attachment, and emotion regulation in children with learning disabilities. Journal of Learning Disabilities, 41(4), 315-332.

Benoit, D., \& Parker, K.C. (1994). Stability and transmission of attachment across three generations. Child Development, 65, 1444-1456.

Berlin, L., Ziv, Y., Amaya-Jackson, L., \& Greenberg, M. (Eds.) (2005). Enhancing early attachments: Theory research, intervention, and policy (pp. 122-127). New York, NY: Guilford.

Bialy, L. (2006). Impact of stress and negative mood on mother and child: Attachment, child development, and intervention (Doctoral dissertation). California Institute of Integral Studies, San Francisco, CA.

Blacher, J., \& Bromley, B. (1987). Attachment and responsivity in children with severe handicaps: Mother and teacher comparison. Child Study Journal, 17(2), 121-133.

Blacher, J., \& Meyers, C.E. (1983). A review of attachment formation and disorder of handicapped children. American Journal of Mental Deficiency, 87(4), 359-371.

Bohlin, G., Hagekull, B., \& Rydell, A. (2000). Attachment and social functioning: A longitudinal study form infancy to middle childhood. Social Development, 9(1), 24-39. 
Bost, K., Vaughn, B., Washington, W., Cielinski, K., \& Bradbard, M. (1998). Social competence, social support, and attachment: Demarcation of construct domains, measurement, and paths of influence for preschool children attending head start. Child Development, 69(1), 192-218.

Bowlby, J. (1969/1982). Attachment and loss: Volume I: Attachment. New York, NY: Basic.

Bowlby, J. (1973). Attachment and loss: Volume II: Separation: Anxiety and anger. New York, NY: Basic.

Bowlby, J. (1988). A secure base: Clinical applications of attachment theory. London, England: Tavistock.

Bradley, R.H., Whiteside, L., \& Mundfrom, D.J. (1994). Early indications of resilience and their relation to experiences in the home environments of low birth weight, premature children living in poverty. Child Development, 65(1), 346-360.

Burgess, K.B., Marshall, P.J., Rubin, K.H., \& Fox, N.A., (2003). Infant attachment and temperament as predictors of subsequent externalizing problems and cardiac physiology. Journal of Child Psychology and Psychiatry, 44(6), 819-831.

Calkins, S.D., \& Fox, N.A. (1992). The relations among infant temperament, security of attachment and behavioral inhibition at twenty-four months. Child Development, 63(1), 1456-1472.

Campbell, S.B., Cohn, J.F., \& Meyers, T. (1995). Depression in first-time mothers: Mother-infant interaction and depression chronicity. Developmental Psychology, 31(3), 349-357.

Cassibba, R., Van IJzendoorn, M., Bruno, S., \& Coppola, G. (2004). Attachment of mothers and children with recurrent asthmatic bronchitis. Journal of Asthma, 41(4), 419-431.

Cassidy, J. (2000). The complexity of the care giving system: A perspective from attachment theory. Psychological Inquiry, 11(2), 86-92.

Clarke-Stewart, K.A., Goossens, F.A., \& Allhusen, V.D. (2001). Measuring infantmother attachment: Is the Strange Situation enough? Social Development, 10(2), 143-170.

Clements, M., \& Barnett, D. (2002). Parenting and attachment among toddlers with congenital anomalies: Examining the strange situation and attachment Q-sort. Infant Mental Health Journal, 23(6), 625-642. 
Clegg, J., \& Sheard, C. (2002). Challenging behavior and insecure attachment. Journal of Intellectual Disability Research, 46(6), 503-506.

Colin, V.L. (1996). Human attachment. Philadelphia, PA: Temple University Press.

Condon, J.T., \& Corkindale, C.J. (1998). The assessment of parent-to-infant attachment: Development of a self-report questionnaire._Journal of Reproductive and Infant Psychology, 16(1), 57-77.

Creasey, G., \& Jarvis, P. (2009). Attachment and marriage. In M.C. Smith \& N. DeFrates-Densch (Eds.), Handbook of Research on adult learning and development (pp. 213-257). New York, NY: Routledge.

Crittenden, P.M. (1988). Relationships at risk. In J. Belsky, T. Nerworski, \& T. Nerworski (Eds.), Clinical implications of attachment (pp. 136-176). Hillsdale, NJ: Erlbaum.

Crowne, D.P., \& Marlowe, D. (1960). A new scale of social desirability independent of psychopathology. Journal of Consulting Psychology, 24(1), 349-354.

Cunningham, J., Harris, G., Vostanis, P., Oyebode, F., \& Blissett, J. (2004). Children of mothers with mental illness: Attachment, emotional and behavioural problems. Early Child Development and Care, 17(8), 639-650.

Doelling, J.L., \& Johnson, J.H. (1990). Predicting success in foster placement: The contribution of parent-child temperament characteristics. American Journal of Orthopsychiatry, 60(4), 585-593.

Easterbrooks, M.A., \& Goldberg, W.A. (1990). Security of toddler-parent attachment: Relation to children's sociopersonality functioning during kindergarten. In M.R. Greenberg \& C. Cicchetti (Eds.), Attachment in preschool years: Theory, research, and interventions (pp. 319-344). Chicago, IL: University of Chicago Press.

Edhborg, M., Lundh, W., Seimyr, L., \& Widstrom, A. (2001). The long-term impact of postnatal depressed mood on mother-child interaction: A preliminary study. Journal of Reproductive and Infant Psychology, 19(1), 61-71.

Egblomasse, S.C. (1999). The development of the Mother-Infant-Toddler Attachment Scale (MITAS) (Doctoral dissertation). Boston, MA: Boston University.

Else-Quest, N.M., Hyde, J.S., Goldsmith, H.H., \& Van Hulle, C.A. (2006). Gender differences in temperament: A meta-analysis. Psychological Bulletin, 132(1), 3372. 
Endriga, M.C., Speltz, M.L., Maris, C.L., \& Jones, K. (1998). Feeding and attachment in infants with and without orofacial clefts. Infant Behavior and Development, 21(4), 699-712.

Feeney, J.A. (2004). Transfer of attachment from parents to romantic partners: Effects of individual and relationship variables. Journal of Family Studies, 10(2), 220-238.

Field, T.M. (2002). Early interactions between infants and their postpartum depressed mothers. Infant Behavior and Development, 23(2), 25-29.

Fraley, R.C., \& Spieker, S.J. (2003). Are infant attachment patterns continuously or categorically distributed? A taxometric analysis of strange situation behavior. Developmental Psychology, 39(3), 387-404.

Gardner, W., Lamb, M.E., Thompson, R.A., \& Sagi, A. (1986). On individual differences in Strange Situation behavior: Categorical and continuous measurement systems in a cross-cultural data set. Infant Behavior and Development, 9(3), 355-375.

Garmezy, N. (1987). Stress, competence, and development: Continuities in the study of schizophrenic adults, children vulnerable to psychopathology and the search for stress-resistant children. American Journal of Othopsychiatry, 57, 159-124.

Greenberg, M.T. (1999). Attachment and psychopathology in childhood. In J. Cassidy \& P.R. Shaver (Eds.), Handbook of attachment: Theory, practice and clinical applications (pp. 346-369). New York, NY: Guilford.

Greenberg, M.T., Speltz, M.L., Deklyen, M., \& Endriga, M.C. (1991). Attachment security in preschoolers with and without externalizing behavior problems: A replication. Development and Psychopathology, 3(4), 413-430.

Grizenko, N. (1994). Risk and protective factors for disruptive behavior disorders in children. Orthopsychiatry, 64(4), 534-544.

Hadadian, A., \& Merbler, J. (1996). Mother's stress: Implications for attachment relationships. Early Child Development and Care, 125(1), 59-66.

Hanson, R.F., \& Spratt, E.G. (2000). Reactive attachment disorder: What we know about the disorder and implications for treatment. Child Maltreatment, 5(2), 137-145.

Harnish, J.D., Dodge, K.A., \& Valente, E. (1995). Mother-child interaction quality as a partial mediator of the roles of maternal depressive symptomatology and socioeconomic status in the development of child behavior problems. Child Development, 66(2), 739-753. 
Heffernan, L., Black, F., \& Poche, P. (1982). Temperament patterns in young neurologically impaired children. Journal of Pediatric Psychology, 74, 415-423.

Heinicke, C., Rineman, N., Ponce, V., \& Guthrie, D. (2008). Relation-based intervention with at-risk mothers: Outcome in the second year of life. Infant Mental Health Journal, 22, 431-462.

Howe, D. (2006). Disabled children, parent-child interaction, and attachment. Child and Family Social Work, 11(2), 95-106.

Hubbs-Tait, L., Hughes, K.P., Culp, A.M., Osofsky, J.D., Hann, D.M., Eberhart-Wright, A., \& Ware, L.M. (1996). Children of Adolescent mothers: Attachment representation, maternal depression, and later behavior problems. American Journal of Orthopsychiatry, 66(3), 416-426.

Huebner, R.A., \& Thomas, K.R. (1995). The relationship between attachment, psychopathology, and childhood disability. Rehabilitation Psychology, 40(2), 111-124.

Huggar, L. (1999). The emotional assessment of infants, toddlers, and preschoolers (Doctoral dissertation). New York, NY: Adelphi University.

Huggar, L., \& Curtis, R. (1999, February). Attachment style questionnaires as predictors of child behavior problems. Poster presented at the annual convention of the American Psychological Association, Boston, MA.

Huntington, G., \& Simeonsson, R. (1993). Temperament and adaptation in infants and young children with disabilities. Infant Mental Health Journal, 14(1), 49-60.

Jacobsen, S.W., \& Frye, K.F. (1991). Effect of maternal social support on attachment: Experimental evidence. Child Development, 62(3), 572-582.

Jacobsen, T., Hibbs, E., \& Ziegenhain, U. (2000). Maternal expressed emotion related to attachment disorganization in early childhood. Journal of Child Psychology and Psychiatry, 41(7), 899-906.

Jameson, P.B., Gelfand, D.M., Kulcsar, E., \& Teti, D.M. (1997). Mother-toddler interaction patterns associated with maternal depression. Development and Psychopathology, 9(1), 537-550.

Janssen, C.G., Schuengel, C., \& Stolk, J. (2002). Understanding challenging behavior in people with severe and profound intellectual disability: A stress-attachment model. Journal of Intellectual Disability Research, 46(6), 445-453. 
Kaplan, P.S., Bachorowski, J., \& Zarlengo-Strouse, P. (1999). Child-directed speech produced by mothers with symptoms of depression fails to promote associative learning in 4-month-old infants. Child Development, 70(3), 560-570.

Kerns, K.A., \& Barth, J.M. (1995). Attachment and play: Convergence across components of parent-child relationships and relations to peer competence. Journal of Social and Personal Relationships, 12(2), 243-260.

Klein, R.P., Suwalsky, J.T.D., McCarthy, M., \& Gist, N.F. (1982). Convergent validity of two measures of attachment. Educational and Psychological Measurement, 42(1), 325-655.

Klopfer, M. (2009). Examining the effectiveness of a multiple antecedent intervention for increasing secure infant attachment (Doctoral dissertation). Milwaukee, WI: Marquette University.

Laible, D.J., \& Thompson, R.A. (2000). Mother-child discourse, attachment security, shared positive affect, and early conscience development. Child Development, 71(5), 1424-1440.

Lambert, M.J., Hansen, N.B., Umphress, V., Lunnen, K., Okiishi, J., Burlingame, G.M., ... Reisinger, C. (1996). Administration and scoring manual for the OQ-45.2. Stevenson, MD: American Professional Credentialing Services.

Lay, K., Waters, E., Posada, G., \& Ridgeway, D. (1995). Attachment security, affect regulation, and defensive responses to mood induction. In E. Waters, B. Vaughn, G. Posada, \& K. Kondo-Ikemura (Eds.), Caregiving, cultural and cognitive perspectives on secure base behavior and working models: New growing points of attachment theory and research. Monographs of the Society for Research in Child Development, 60(2-3), 179-196.

Lederberg, A., \& Mobley, C. (1990). The effect of hearing impairment on the quality of attachment and mother-toddler interaction. Child Development, 61(5), 1596-1605.

Lerner, R.M., Palermo, M., Spiro, A., \& Nesselroade, J. (1982). Assessing the dimensions of temperament individuality across the lifespan: The Dimensions of Temperament Survey. Child Development, 53(2), 149-159.

Lieberman, A., \& Van Horn, P. (2007). Psychotherapy with infants and young children: repairing the effects of stress and trauma on early attachment (pp. 17-18). New York, NY: Guilford. 
Lyons-Ruth, K., Alpern, L., \& Repacholi, B. (1993). Disorganized infant attachment classification and maternal psychosocial problems as predictors of hostile aggressive behavior in the preschool classroom. Child Development, 64(4), 572585.

Lyons-Ruth, K., Easterbrooks, M.A., \& Cibelli, C.D. (1997). Infant attachment strategies, infant mental lag, and maternal depressive symptoms; predictors of internalizing and externalizing problems at age 7. Developmental Psychology, 33(4), 681-692.

Lyons-Ruth, K., \& Jacobvitz, D. (2008). Attachment disorganization: Genetic factors, parenting contexts, and developmental transformation from infancy to adulthood. In J. Cassidy \& P. Shaver (Eds.), Handbook of attachment: Theory, research, and clinical applications ( $2^{\text {nd }}$ ed., pp. 666-697). New York, NY: Guilford.

Main, M., \& Solomon, J. (1990). Procedures for identifying infants as disorganized/ disoriented during the Ainsworth Strange Situation. In M.T. Greeenberg, D. Cicchetti, \& E.M. Cummings (Eds.), Attachment in the preschool years: Theory, research, intervention (pp. 88-112). Chicago, IL: University of Chicago Press.

Maldonado-Duran, J.M. (2002). Infant and toddler mental health: Models of clinical intervention with infants and their families. Washington, DC: American Psychiatric Publishing.

Manassis, K., Bradley, S., Goldberg, S., Hood, J., \& Swinson, R.P. (1995). Behavioural inhibition, attachment and anxiety in children of mothers with anxiety disorders. Canadian Journal of Psychiatry, 40(2), 87-92.

Mangelsdorf, S.C., \& Frosch, C.A., (2000). Temperament and attachment: One construct or two. Advances in Child Development and Behavior, 26(3), 181-220.

Mangelsdorf, S.C., McHale, J.L., Diener, M., Goldstein, L.H., \& Lehn, L. (2000). Infant attachment: Contribution of infant temperament and maternal characteristics. Infant Behavior and Development, 23(3), 175-196.

Mangelsdorf, S., Plunkett, J., Dedrick, C., Berlin, M., Meisels, S., \& McHale, J. (1996). Attachment security in extremely-low-birth weight infants. Developmental Psychology, 32(2), 914-920.

Maris, C.L., Endriga, M.C., Speltz, M.L., \& Jones, K., \& DeKlyen, M. (2000). Are infants with orofacial clefts at risk for insecure mother child attachments? Cleft Palate Craniofacial Journal, 37(1), 257-265. 
Martins, C., \& Gaffan, E.A. (2000). Effects of early maternal depression on patterns of infant-mother attachment: A meta-analytic investigation. Journal of child Psychology and Psychiatry, 41(6), 737-746.

Marvin, R., Cooper, G., Hoffman, K., \& Powell, B. (2002). The circle of security project: Attachment-based intervention with caregiver-preschool child dyads. Attachment and Human Development, 4, 107-124.

Marvin, R.S., \& Pianta, R.C. (1996). Mothers' reactions to their child's diagnosis: Relation with security of attachment. Journal of Clinical Child Psychology, 25(4), 436-445.

Mikulincer, M., Gillath, O., Spair-Lavid, Y., Yaakobi, E., Arias, K., Tal-Aloni, L., \& Bor, G. (2003). Attachment theory and concern for others' welfare: Evidence that activation of the sense of secure base promotes endorsement of self-transcendence values. Basic and Applied Social Psychology, 25(4), 299-313.

Moran, G., Pederson, D., Pettit, P., \& Krupka, A. (1992). Maternal sensitivity and infantmother attachment in a developmentally delayed sample. Infant Behavior and Development, 15(1), 427-442.

Mrazek, D.A., Casey, B., \& Anderson, I. (1987). Insecure attachment in severely asthmatic preschool children: Is it a risk factor? Journal of the American Academy of Child and Adolescent Psychiatry, 26(4), 516-520.

Muller, M.E. (1994). A questionnaire to measure mother-to-infant attachment. Journal of Nursing Measurement, 2(2), 129-141.

Murphy, A. (2010, July). Bridging the gap. Paper presented at the Clinical Application of Attachment Theory and Research Conference, Salt Lake City, UT.

Nicely, P., Tamis-LeMond, C.S., \& Grolnick, W.S. (1999). Maternal responsiveness to infant affect: Stability and prediction. Infant Behavior and Development, 22(1), 103-117.

Oppenheim, D. (2001). Mothers' empathic understanding of their preschoolers' internal experience: Relations with early attachment. International Journal of Behavior Development, 25(1), 16-26.

Oppenheim, D., \& Goldsmith, D. (2007). Attachment theory in clinical work with children: Bridging the gap between research and practice. New York, NY: Guilford. 
Oppenheim, D., Koren-Karie, N., \& Sagi, A. (1999). Mothers' empathetic understanding of their preschoolers' internal experience: Relations with early attachment. International Journal of Behavior Development, 25(1), 16-26.

Park, K.A., \& Waters, E. (1989). Security of attachment and preschool friendships. Child Development, 60(5), 1076-1081.

Pauli-Pott, U., Haverkock, A., Pott, W., \& Beckmann, D. (2007). Negative emotionality, attachment quality, and behavior problems in early childhood. Infant Mental Health Journal, 28(1), 39-53.

Pederson, D., Gleason, K., Moran, G., \& Bento, S. (1998). Maternal attachment representations, maternal sensitivity, and the infant-mother attachment relationship. Developmental Psychology, 34(5), 925-933.

Pederson, D.R., \& Moran, G. (1995). The relationship imperative: Arguments for a broad definition of attachment. Journal of Family Psychology, 13(4), 496-500.

Peterson, G. (1987). Prenatal bonding, prenatal communication and the prevention of prematurity. Journal of Prenatal and Perinatal Psychology and Health, 2(2), 8792.

Prugh, D.G., Staub, E., Sands, J.R., Kirshbaum, R.M., \& Lenihan, E.A. (1953). A study of emotional reactions of children and families to hospitalization and illness. American Journal of Orthopsychiatry, 23(1), 70-106.

Raver, C.C., \& Zigler, E.F. (1997). Focus section: New perspectives on Head Start: Social competence: An untapped dimension in evaluating Head Start's success. Early Childhood Research Quarterly, 12(4), 363-385.

Robinson, J.R. (1995). Quality of attachment as a predictor of parental visitation when a young child or infant is hospitalized (Master's thesis). Des Moines, IA: Drake University.

Robinson, J.R., Rankin, J.L., \& Drotar, D. (1996). Quality of attachment as a predictor of maternal visitation to young hospitalized children. Journal of Pediatric Psychology, 21(3), 401-417.

Rosen, K.S., \& Rothbaum, F. (1993). Quality of parental care giving and security of attachment. Developmental Psychology, 29(2), 358-367.

Sameroff, A.J., \& Emde, R.N. (Eds.). (1989). Relationship disturbances in early childhood: A developmental approach. New York, NY: Basic. 
Schaeffer, J.R., \& Emerson, P.E. (1984). The development of social attachments in infancy. Monographs of the Society for Research in Child Development, 39(3), 177.

Schneider, B., Atkinson, L., \& Tardif, C. (2001). Child-parent attachment and children's peer relations: A quantitative review. Developmental Psychology, 37(1), 86-100.

Scopesi, A., Viterbori, P., Sponza, S., \& Zucchinetti, P. (2004). Assessing mother-to infant attachment: The Italian adaptation of a self-report questionnaire. Journal of Reproductive and Infant Psychology, 22(2), 99-109.

Seibert, A.C. (2010). Processes linking parent-child attachment and peer relationships (Doctoral dissertation). Kent, OH: Kent State University.

Shanahan, M., Roberts, J., Hatton, D., Reznick, J., \& Goldsmith, H. (2008). Early temperament and negative reactivity in boys with fragile $\mathrm{X}$ syndrome. Journal of Intellectual Disability Research, 52, 842-854.

Sheeran, T., Marvin, R.S., \& Pianta, R.C. (1997). Mothers' resolution of their child's diagnosis and self-reported measures of parenting stress, marital relations, and social support. Journal of Pediatric Psychology, 22(2), 197-212.

Silber, S. (1989). Family influences on early development. Topics in Early Childhood Special Education, 8(4), 1-23.

Sloan, E.P., Maunder, R.G., Hunter, J.J., \& Moldofsky, H. (2007). Insecure attachment is associated with the a-EEG anomaly during sleep. Biosocial Medicine, 1(3), 20-26.

Solomon, J., \& George, C. (1999a). Attachment disorganization. New York, NY: Guilford.

Solomon, J., \& George, C. (1999b). The measurement of attachment security. In J. Cassidy \& P.R. Shaver (Eds.), Handbook of attachment (pp. 383-418). New York, NY: Guilford.

Solomon, J., \& George, C. (2008). The measurement of attachment security. In J. Cassidy \& P. R. Shaver (Eds.) Handbook of attachment (pp. 383-418). New York, NY: Guilford.

Speltz, M.L., Edriga, M.C., Fisher, P.A., \& Mason, C.A. (1997). Early predictors of attachment in infants with cleft lip and/or palate. Child Development, 68(1), 1225. 
Speltz, M.L., Greenberg, M.T., \& Deklyen, M. (1990). Attachment in preschoolers with disruptive behavior: A comparison of clinic-referred and no problem children. Developmental and Psychopathology, 2(1), 31-46.

Sroufe, L.A., Duggal, S., Weinfield, N., \& Carlson, E. (2000). Relationships, development, and psychopathology. In A.J. Sameroff, M. Lewis, \& S.M. Miller (Eds.), Handbook of developmental psychopathology ( $2^{\text {nd }}$ ed., pp. 366-359). New York, NY: Kluwer Academic Plenum.

Svanberg, P. (2009). Promoting secure attachment through early screening and interventions: A partnership approach. In J. Barlow \& P. Svanberg (Eds.), Keeping the baby in mind: Infant mental health in practice (pp. 33-67). New York, NY: Routledge.

Tannock, R. (1988). Control and reciprocity in mothers' interactions with Down syndrome and normal children. In K. Marfo (Ed.), Parent-child interaction and developmental disabilities (pp. 163-180). New York, NY: Praeger.

Tarabulsy, G.M., Avgoustis, E., Phillips, J., Pederson, D.R., \& Moran, G. (1997). Similarities and differences in mothers' and observers' descriptions of attachment behaviors. International Journal of Behavioral Development, 21(3), 599-621.

Teti, D.M., \& Gelfand, D.M. (1997). The preschool assessment of attachment: Construct validity in a sample of depressed and non-depressed families. Development and Psychopathology, 9(3), 517-536.

Teti, D.M., Gelfand, D.M., Messinger, D.S., \& Isabella, R. (1995). Maternal depression and the quality of early attachment: An examination of infants, preschoolers, and their mothers. Developmental Psychology, 31(3), 364-376.

Teti, D.M., \& McGourty, S. (1996). Using mothers versus trained observers in assessing children's secure base behavior: Theoretical and methodological considerations. Child Development, 67(2), 597-605.

Teti, D.M., Nakaqawa, M., Das, R., \& Wirth, O. (1991). Security of attachment between preschoolers and their mothers: Relations among social interaction, parenting stress, and mothers' sorts of attachment Q-set. Developmental Psychology, 27(3), 440-447.

Thomas, A., Chess, S., \& Birch, H.G. (1968). Temperament and behavior disorders in children. Oxford, England: New York University Press. 
Van Bakel, H.J.A., \& Riksen-Walraven, M. (2004). AQS security scores: What do they represent? A study in construct validation. Infant Mental Health Journal, 25(3), 175-193.

Van IJzendoorn, M., Goldberg, S., Kroonenberg, P., \& Frenkel, O. (1992). The relative effects of maternal and child problems on the quality of attachment: A meta analysis of attachment in clinical samples. Child Development, 63(4), 840-858.

Van IJzendoorn, M.H., Schuengel, C., \& Bakermans-Kranenburg, M.J. (1999). Disorganized attachment in early childhood: Meta-analysis of precursors, concomitants and sequelae. Development and Psychopathology, 11(2), 225-249.

Van Ijzendoorn, M.H.,Vereijken, C.M.J.L., Bakersmans-Kranenburg, M.J., \& RiksenWalraven, J.M. (2004). Assessing attachment security with the attachment Q sort: Meta-analytic evidence for the validity of the observer AQS. Child Development, 75(4), 1188-1213.

Vaughn, B.E., \& Bost, K. (1999). Attachment and temperament: Redundant, independent, or interacting influences on interpersonal adaptation and personality development? In J. Cassidy \& P. Shaver (Eds.), Handbook of attachment (pp. 198-225). New York, NY: Guilford .

Vaughn, B.E., \& Waters, E. (1990). Attachment behavior at home and in the laboratory: Q-sort observations and Strange Situation classification of one-year-olds. Child Development, 61(6), 1965-1973.

Ward, M.J., Lee, S.S., \& Lipper E.G. (2000). Failure-to-thrive is associated with disorganized infant-mother attachment and unresolved maternal attachment. Infant Mental Health Journal, 21(6), 428-444.

Wartner, U.G., Grossman, K., Fremmer-Bombik, E., \& Suess, G. (1994). Attachment Patterns at age six in south Germany: Predictably from infancy and implications for preschool behavior. Child Development, 65(4), 1014-1027.

Wasserman, G., Lennon, M., Allen, R., \& Shilansky, M. (1987). Contributors to attachment in normal and physically handicapped infants. Journal of the American Academy of Child and Adolescent Psychiatry, 26(1), 9-15.

Waters, E., \& Deane, K.E. (1985). Defining and assessing individual differences in Attachment relationships: O methodology and the organization of behavior in Infancy and early childhood. In I. Brotherhood \& E. Waters (Eds.) Growing points of attachment theory and research. Monographs of the Society for Research in Child Development, 50(1-2), 41-65. 
Waters, E. (1997). Assessing secure base behavior and attachment security using the Qsort method. Retrieved from, http://waters.socialpsychology.org

Waters, E., \& Deane, K.E. (1985). Defining and assessing individual differences in attachment relationships: Methodology and the organization of behavior in Infancy and early childhood. In I. Brotherhood \& E. Waters (Eds.), Growing points of attachment theory and research. Monographs of the Society for Research in Child Development, 50(1-2), 41-65.

Waters, E., Hamilton, C.E., \& Weinfield, N.S. (2000). The stability of attachment security from infancy to adolescence and early adulthood: General introduction. Child Development, 57(1), 56-65.

Weber, R.A., Levitt, M.J., \& Clark, M.C. (1986). Individual variation in attachment security and Strange Situation behavior: The role of maternal and infant temperament. Child Development, 57(1), 56-65.

Wellemsen-Swinkels, S.H.N., Bakermans-Kranenburg, M.J., Buitelaar, J.K., Van IJzendoorn, M.H., \& England, H. (2000). Insecure and disorganized attachment in children with a pervasive developmental disorder: Relationship with social interaction and heart rate. Journal of Child Psychology and Psychiatry, 41(6), 759-767.

Werner, E.E. (1989). High risk children in young adulthood: A longitudinal study from birth to 32 years. American Journal of Orthopsychiatry, 59(1), 72-81.

Werner, E.E., \& Smith, R.S. (1992). Overcoming the odds: High risk children from birth to adulthood. Ithaca, NY: Cornell University Press.

Windle, M. (1989). Temperament and personality: An exploratory interinventory study of the DOTS-R, EASI-II, and EPI. Journal of Personality Assessment 53(3), 685692.

Windle, M. (1992). Revised Dimensions of Temperament Survey (DOTS-R):

Simultaneous group confirmatory factor analysis for adolescent gender groups. Psychological Assessment, 4(2), 228-234.

Windle, M., \& Lerner, R.M. (1986). Reassessing the dimensions of temperamental individuality across the life span: The Revised Dimensions of Temperament Survey (DOTS-R). Journal of Adolescent Research, 27(1), 213-230.

Wittmer, D., Doll, B., \& Strain, P. (1996). Social and emotional development in early childhood: The identification of competence and disabilities. Journal of Early Intervention, 20(4), 299-318. 
Wu, F., \& Zou, H. (1995). The association between attachment quality and peer relationships of preschool children. Acta Psychologia Sinica, 27(4), 434-441.

Zeanah, C.H., Boris, N.W., \& Leiberman, A.F. (2000). Attachment disorders of infancy. In A.J. Sameroff \& M. Lewis (Eds.), Handbook of developmental psychopathology ( $2^{\text {nd }}$ ed., pp. 293-307). Dordrecht, Netherlands: Kluwer.

Zion, E., \& Jenvey, V.B. (2006). Temperament and social behavior at home and school among typically developing children and children with intellectual disability. Journal of Intellectual Disability Research, 50, 445-456. 
APPENDICES 
Appendix A

Time 1 Letter and Parent Questionnaire 


\section{Uthatstate UNIVERSITY}

DEPARTMENT OF PSYCHOLOGY

2810 Old Main Hill

Logan UT 84322-2810

Telephone: (435) 797-1460

FAX: (435) 797-1448

February 10, 2005
Date Created: March 10,2005

Page 1 of 1

Utah State University IRB Approved 3/10/2005
Approval terminates 3/09/2006.

IRB Password Protected per True M. Rubal, IRB Administrator

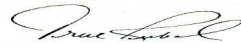

Dear

We hope you will be interested in helping us with some very important research.

Dr. Gretchen Gimpel, in the Department of Psychology at Utah State University (USU) and Mary LaMont, doctoral student and school psychologist working with the Weber-Morgan Early Intervention Program), are conducting a research study to gain important information that may lead to improved services for children with developmental delays.

This study will involve two parts. In the first part, if you give consent to participate, you will be asked to complete questionnaires about yourself and your child. The questionnaires will cover information about your child's behavior and your stress as a parent. In addition, we are asking you to allow the researcher to obtain information about your child from his or her early intervention file. Names of all participants will be included in a drawing for cash gifts after this part of the study.

For the second part of the study, the researcher will contact you in one year and ask you to complete the same questionnaires. At this time, with your consent, your child's preschool teacher will complete a questionnaire about your child's behavior at preschool. A second drawing for cash gifts will be conducted after this part of the study.

In both parts of this study, your name and your child's name will be kept confidential, and information about you and your child will be connected to an assigned number rather than your name.

Please find the informed consent form with this letter. If you wish to participate in this study, please mark yes on the form, sign it, and return in the addressed, stamped envelope.

If you do not wish to participate, please mark no on the form and return.

I would be glad to answer other questions about this research. Thank you for considering participation.

Sincerely,

$N G \cdot N$

Dr. Gretchen Gimpel

Principal Investigator

Dept. of Psychology

Utah State University

(435) 797-0721

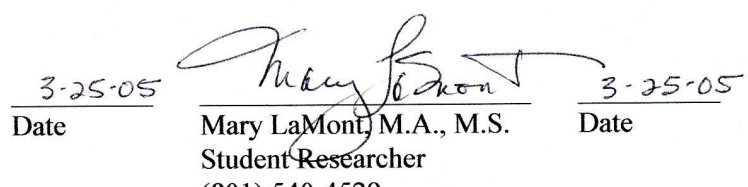

(801) 540-4529 


\section{Parent Questionnaire}

To be completed by the child's mother:

Child's name

Child's age

Mother's name

Mother's age

Mother's ethnicity

Child's ethnicity

Mother's Marital Status

Ages of brothers and sisters in home

Mother's highest educational level (circle one)

Did not

High School

Some

Graduate from

High School

Graduate

College

College

Graduate

Graduate

Professional

(BA/BS)

Degree

Father's highest educational level (circle one)

Did not

High School

Some

Graduate from

Graduate

College

College

Graduate

High School

(BA/BS)

Graduate

Professional

Degree

Number of hours Mother works outside of the home per week

Number of hours Father works outside of the home per week

Approximate household income (circle one)

$\begin{array}{lllllll}\text { Less than } & 10,000- & 20,000- & 35,000- & 50,000- & 75,000- & \text { More than } \\ 10,000 & 20,000 & 35,000 & 50,000 & 75,000 & 100,000 & 100,000\end{array}$

Please provide names, addresses and phone numbers of two people who will know how to contact you, in case you move. Thank you.

Name

Address

Phone Number

Name

Address

Phone Number 
Appendix B

Time 2 Letter and Parent Questionnaire 
Dear Study Participant,

It has been a little over one year since you agreed to participate in and completed the first set of questionnaires for my research study: Mother-child attachment and preschool behavior problems for children with developmental delays.

Thank you so much for your time in completing those first questionnaires. It is now time to collect the second round of information from you.

I have included a second copy of the consent form you signed previously. If you have any questions please contact me or my supervisor at the numbers listed on that consent form.

The questionnaires are almost identical to the ones you completed a year ago. I know they are somewhat lengthy, but it is anticipated that the information gathered will be of great value to early intervention and preschool programs throughout the nation.

In addition to the drawing for $\$ 50$ and $\$ 25$ cash prizes upon the return of all participants' questionnaires, I will be sending $\$ 5$ to each participant upon receipt of each set of completed questionnaires. I am fully aware that this does not compensate for your time and effort involved, but it is a small token of my appreciation.

Best wishes to you!

Sincerely,

Mary LaMont, M.A., M.S.

Educational Psychologist

Graduate student

Utah State University 


\section{Parent Questionnaire}

Child's name:

Mother's name:

Mother's marital status:

Ages of brothers and sisters in home

Number of Mother works outside of the home per week

Number of hours Father works outside of the home per week

Approximate household income per year (circle one)

$\begin{array}{lllllll}\text { Less than } & 10,000- & 20,000- & 35,000- & 50,000- & 75,000- & \text { More than } \\ 10,000 & 20,000 & 35,000 & 50,000 & 75,000 & 100,000 & 100,000\end{array}$

Will your child attend preschool? Yes No

Please provide the name and address of the school: 
Appendix C

Informed Consent 


\title{
Utah State
}

UNIVERSITY

November 23, 2004

Page 1 of 2

\author{
Informed Consent Form \\ Mother-Child Attachment and Preschool Behavior Problems for Children with \\ Developmental Delays
}

Gretchen Gimpel, PhD., a faculty member in the Psychology Department at Utah State University and Mary LaMont a school psychologist and doctoral student in psychology will conduct this study.

Purpose: The purpose of this study is to gain more information about mother-child relationships and behavior problems in children with developmental delays. This information will help the Weber Morgan Early Intervention Program (as well as other early intervention programs) determine the most effective services to promote the positive emotional and behavioral outcomes for children with developmental delays.

Procedures: If you agree to participate in this study, you will be asked to complete a series of simple questionnaires now and one year later. If you consent to participate a packet of questionnaires and a return envelope will be sent to you. In addition, if you agree to participate, you give us permission to access your child's early intervention file which includes your child's area(s) of developmental delay and test scores. Upon completion of the questionnaires your name will be entered in a drawing for $\$ 25$ and $\$ 50$ cash gifts. You will be contacted if you have won a gift. You will also be contacted after one year to obtain permission for completion of a second series of questionnaires and to obtain information from your child's preschool teacher through the use of teacher questionnaire. A second drawing for cash gifts will be conducted.

Risks: There are no serious, known risks involved with participating in this study. The questionnaires ask about your feelings and knowledge about you and your child. You could experience positive or negative feelings when completing the questionnaires. You may discontinue the study if you do not feel comfortable. If there are any unforeseen risks identified, you will be immediately informed. If you have concerns about yourself or your child, you can seek help from such places as Weber County Mental Health (801-629-5800).

Benefits: You or your child may not benefit directly from this research study. The information gained by this study, however, could potentially help early intervention programs and researchers understand mother-child relationships and behavior problems in children with developmental delays. This would be beneficial in helping early intervention program workers and researchers develop treatment programs to help prevent behavior problems for children with developmental delays. 
November 23, 2004

2 of 2

\author{
Mother-Child Attachment and Preschool Behavior Problems for Children with \\ Developmental Delays
}

Voluntary Nature of Participation and Right to Withdraw without Consequence: Participation in this research is entirely voluntary. You may refuse to participate or withdraw from the study at any time without negative consequences. This will not affect your child's early intervention services in any way.

Confidentiality: Information about you and your child will be kept confidential and will be available only to individuals involved in the research. You will be assigned a code number. Only this number will be used when the data are stored in the computer. Public presentations of the results of this study will in no way identify you or your child. All data will be kept in a locked file cabinet, which will be accessible only by the researchers. Data will be destroyed after 5 years.

IRB Approval Statement: The Institutional Review Board (IRB) for the protection of human participants at Utah State University has reviewed and approved this research project. You can contact the IRB at 435-797-1821 if you have questions or concerns about this project.

Copy of Consent: This letter contains two copies of this Informed Consent Form. Please sign both and retain one copy for your files. Please return one signed copy in the envelope provided.

Signature of Mother: (Please check one and sign if agreeing to participate)

Yes, I want to participate in this study.

I have read this form and understand the purpose of this project. I also understand the potential risks and benefits involved, and what to do and who to contact if I have any concerns. If I have other question, I understand that I may contact the researcher at phone numbers listed below. By signing this document, I agree to participate in this study.

Mother's signature

Mother's printed name

Child's printed name

No, I do not want to participate in this study.

Signatures of researchers:

Gretchen Gimpel, Ph.D.

Principal Investigator

435-797-0721
Mary LaMont, M.A., M.S.

Student Researcher

801-540-4529 
Appendix D

Measures 


\section{Attachment Q-Sort Questionnaire \\ AQSQ}

The following questions have to do with your child's behavior. You are to consider your child's behavior during a 7 day period when he or she was not ill. Please read all parts of the question. Circle the number that best represents your child.

1. When my child is upset or injured, he/she will accept comforting from adults other than me. (Low score: You are the only one he/she allows to comfort him/her.)

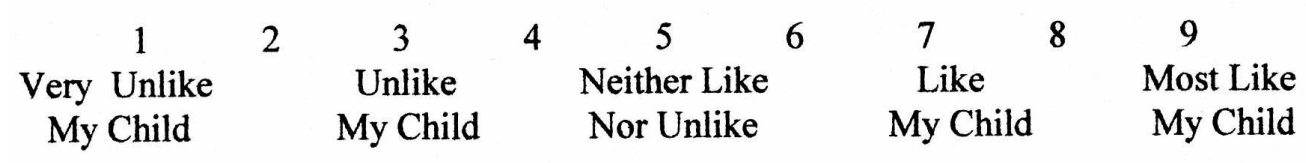

2. My child acts like he/she expects me to interfere with his/her activities when I am simply trying to help him/her with something. (Low score: Accepts your help readily, unless you are in fact interfering.)

$$
\begin{array}{llllllllll}
1 & 2 & 3 & 4 & 5 & 6 & 7 & 8 & 9
\end{array}
$$

3. My child is lighthearted and playful most of the time.

$$
\begin{array}{lllllllll}
1 & 2 & 3 & 4 & 5 & 6 & 7 & 8 & 9
\end{array}
$$

4. When given a choice, my child would rather play with toys than adults. (Low score: Would rather play with adults than toys.)

$$
\begin{array}{lllllllll}
1 & 2 & 3 & 4 & 5 & 6 & 7 & 8 & 9
\end{array}
$$

5. If held in my arms, my child stops crying and quickly recovers after being frightened or upset. (Low score: Not easily comforted.)

$$
\begin{array}{lllllllll}
1 & 2 & 3 & 4 & 5 & 6 & 7 & 8 & 9
\end{array}
$$

6. My child copies behaviors or ways of doing things from watching my behavior. (Low score: Doesn't noticeably copy your behavior.)

$$
\begin{array}{llllllllll}
1 & 2 & 3 & 4 & 5 & 6 & 7 & 8 & 9
\end{array}
$$

7. When I don't do what my child wants right away, he/she behaves as if I were not going to do it at all (fusses, gets angry, walks off to other activities, etc.). (Low score: Wait's a reasonable time, as if he expects I will shortly do what he asked.)

$$
\begin{array}{lllllllll}
1 & 2 & 3 & 4 & 5 & 6 & 7 & 8 & 9
\end{array}
$$

8. My child readily lets new adults hold or share things he/she has, if they ask to.

$\begin{array}{llllllllll}1 & 2 & 3 & 4 & 5 & 6 & 7 & 8 & 9\end{array}$




\section{AQSQ}

9. My child keeps track of my location when he/she plays around the house (calls to me now and then, notices me go from room to room, notices if I change activities). (Low score: Doesn't keep track.

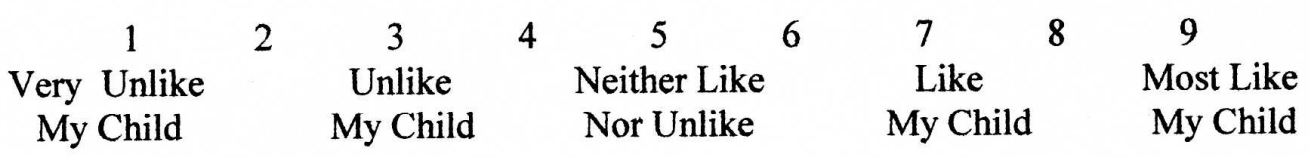

10. My child tries to get me to imitate him/her, or quickly notices and enjoys it when I imitate him/her on my own.

$\begin{array}{llllllllll}1 & 2 & 3 & 4 & 5 & 6 & 7 & 8 & 9\end{array}$

11. If I laugh at or approve of something my child has done, he/she repeats it again and again.

$\begin{array}{llllllllll}1 & 2 & 3 & 4 & 5 & 6 & 7 & 8 & 9\end{array}$

12. If I move very far, my child follows along and continues his/her play in the area I have moved to. (Doesn't have to be called or carried along; doesn't stop play or get upset.)

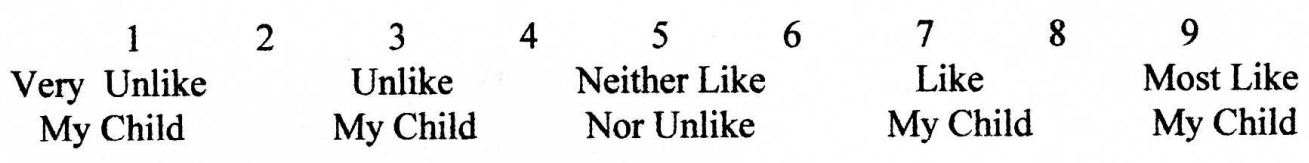

Please comment on other things that have to do with your relationship with your child.

Please comment on other things that have to do with your feelings for your child. 


\section{CHILD ATTACHMENT QUESTIONNAIRE}

(CAQ)

Please check which description describes your child's behavior best between the ages of 12 and 18 months. If your child is older than 18 months-please try and recall which statement best described your child at that time of his/her life.

\section{PLEASE CHECK ONLY ONE OF THE FOLLOWING STATEMENTS:}

My child actively explores a new environment, outside the home. When I return to my child after being away from him/her, my child tends to greet and /or seek contact with me and is able to return to play now that $I$ am present.

My child tends to explore a new environment, outside the home, without interaction with me. When I return after being away from him/her, my child avoids or ignores me. Generally, my child interacts with me and strangers in similar manner. My child tends to cry more when left alone than with a stranger.

My child tends to be upset by an unfamiliar room or adult even when I am present. In a new environment, outside the home, my child tends to not explore this new room and becomes very upset if I leave the room. When I return, after being away from my child, he/she is difficult to comfort and often shows anger.

My child does not have a typical way of responding to new environments. Upon reunion, my child may either withdrew from me or be angry and difficult to comfort. My child may go back and for the from withdrawal to angry and/or be difficult to comfort when I return after leaving him/her in a new environment. 


\title{
Dimensions of Temperament-Revised
}

Please respond to these items as they apply to your child. It is best to indicate what you really think. Don't spend too much thinking about each question. Give the first, natural answer as it comes to you.

$\begin{array}{llll}\text { Usually } & \text { More TRUE } & \text { More FALSE } & \text { Usually } \\ \text { TRUE } & \text { than false } & \text { than true } & \text { FALSE }\end{array}$

1. It takes my child a long time to get used to a new thing in the home

1

2

3

4

2. My child cant stay still for long.

1

2

3

4

3. My child laughs and smiles at

a lot of things.

1

2

4

4. My child wakes up at different times.

\author{
1
}

2

3

5. Once my child is involved in a task, nothing can distract him or her from it.

6. My child persists at a task until it's finished.

\section{2}

3

4

7. My child moves around a lot.

1

2

3

4

8. My child can make him/herself at home anywhere.

9. My child can always be distracted by something else, no matter what he or she may be doing.

10. My child stays with an activity for a long time.

11. If my child has to stay in one place for a long time, he/she gets very restless.

12. My child usually moves toward new objects shown to him/her.

2 


$\begin{array}{llll}\text { Usually } & \text { More TRUE } & \text { More FALSE } & \text { Usually } \\ \text { TRUE } & \text { than false } & \text { than true } & \text { FALSE }\end{array}$

13. It takes my child a long time to adjust to new schedules.

1

2

3

4

14. My child does not laugh or smile at many things.

15. If my child is doing one thing, something else occurring won't get him/her to stop.

16. My child eats about the same amount for dinner whether he/she is home, visiting someone or traveling.

17. My child's first reaction is to reject something new or unfamiliar to him/her.

18. Changes in plans make my child restless.

19. My child often stays still for long periods of time.

20. Things going on around my child can not take him/her away from what he/she is doing.

21. My child takes a nap, rest or break at the same time every day.

22. Once my child takes something up, he/she stays with it.

23. Even when my child is supposed to be still, he/she gets very fidgety after a few minutes.

24. My child is hard to distract.

25. My child usually gets the same amount of sleep each night.

26. On meeting a new person my child tends to move toward him or her. 


$\begin{array}{llll}\text { Usually } & \text { More TRUE } & \text { More FALSE } & \begin{array}{l}\text { Usually } \\ \text { TRUE }\end{array} \\ \text { than false } & \text { than true } & \text { FALSE }\end{array}$

27. My child gets hungry about the same time every day.

2

3

4

28. My child smiles often.

2

3

4

29. My child never seems to stop moving.

30. It takes my child no time at all to get used to new people.

31. My child usually eats the same amount each day.

2

4

32. My child moves a great deal in his/her sleep.

2

4

33. My child seems to get sleepy just about the same time every night.

2

34. I do not find my child laughing often.

35. My child moves toward new situations.

36. When my child is away from home he/she still wakes up at the same time each morning.

37. My child eats about the same amount of breakfast from day to day.

38. My child moves a lot in bed.

2

39. My child feels full of pep and energy at the same time each day.

40. My child has bowel movements at about the same time each day.

1

41. No matter when my child goes to sleep, he/she wakes up at the same time the next morning. 
Usually

TRUE
More TRUE than false
More FALSE than true
Usually

FALSE

42. In the morning, my child is still in the same place as he/she was when he/she fell asleep.

43. My child eats about the same amount of supper from day to day.

44. When things are out of place, it takes my child a long time to get used to it.

45. My child wakes up at the same time on weekends and holidays as on other days of the week.

46. My child doesn't move around much at all in his/her sleep.

47. My child's appetite seems to stay the same day after day.

48. My child's mood is generally cheerful.

49. My child resists change in routine.

50. My child laughs several times a day.

51. My child's first response to anything new is to move his or her head toward it.

52. Generally, my child is happy.

53. The number of times my child has a bowel movement on any day varies from day to day.

54. My child never seems to be in the same place for long. 


\section{Marlowe-Crowne Social Desirability Scale Personal Reaction Inventory}

Listed below are a number of statements concerning personal attitudes and traits. Read each item and decide whether the statement is true or false as it pertains to you personally.

T F 1. Before voting, I thoroughly investigate the qualifications of all the candidates.

T F 2. I never hesitate to go out of my way to help someone in trouble.

T F 3. It is sometimes hard for me to go on with my work if I am not encouraged.

T F 4. I have never intensely disliked someone.

T F 5. On occasion I have had doubts about my ability to succeed in life.

T F 6. I sometimes feel resentful when I don't get my way.

T F 7. I am always careful about my manner of dress.

T F 8. My table manners at home are as good as when I eat out at a restaurant.

T F 9. If I could get into a movie without paying and be sure I was not seen, I would probably do it.

$\mathrm{T} \quad \mathrm{F} \quad$ 10. On a few occasions, I have given up doing something because $\mathrm{I}$ thought too little of my ability.

T $\quad \mathrm{F}$ 11. Ilike to gossip at times.

T $\quad$ 12. There are times when I felt like rebelling against people in authority even though I knew they were right.

$\mathrm{T} \quad \mathrm{F}$ 13. No matter who I'm talking to, I'm always a good listener.

T F 14. I can remember "playing sick" to get out of something.

T F 15. There have been occasions when I took advantage of someone.

$\mathrm{T} \quad \mathrm{F} \quad$ 16. I'm always willing to admit it when I make a mistake.

$\mathrm{T} \quad \mathrm{F} \quad$ 17. I always try to practice what I preach.

T F 18. I don't find it particularly difficult to get along with loud-mouthed, obnoxious people.

T $\quad$ F 19. I sometimes try to get even rather than forgive and forget. 
T F 20. When I don't know something I don't at all mind admitting it.

T F 21. I am always courteous, even to people who are disagreeable.

T F 22. At times I have really insisted on having things my own way.

T F 23. There have been occasions when I felt like smashing things.

T F 24. I would never think of letting someone else be punished for my wrongdoings.

$\mathrm{T} \quad \mathrm{F}$ 25. I never resent being asked to return a favor.

T F 26. I have never been irked when people expressed ideas very different from my own.

T F 27. I never make a long trip without checking the safety of my car.

T $\quad$ 28. There have been times when I was quite jealous of the good fortune of others.

T $\quad$ 29. I have almost never felt the urge to tell someone off.

T F 30. I am sometimes irritated by people who ask for favors of me.

T $\quad$ 31. I have never felt that I was punished without cause.

T F 32. I sometimes think when people have a misfortune they only got what they deserved.

T F 33. I have never deliberately said something that hurt someone's feelings. 


\section{Uutcome Questionnaire (UQ-4).L)}

To be completed by the child's mother.

Looking back over the last week, including today, help us understand how you have been feeling. Read each item carefully and mark the box under the category which best describes your current situation. For this questionnaire, work is defined as employment, school, housework, volunteer work, and so forth.

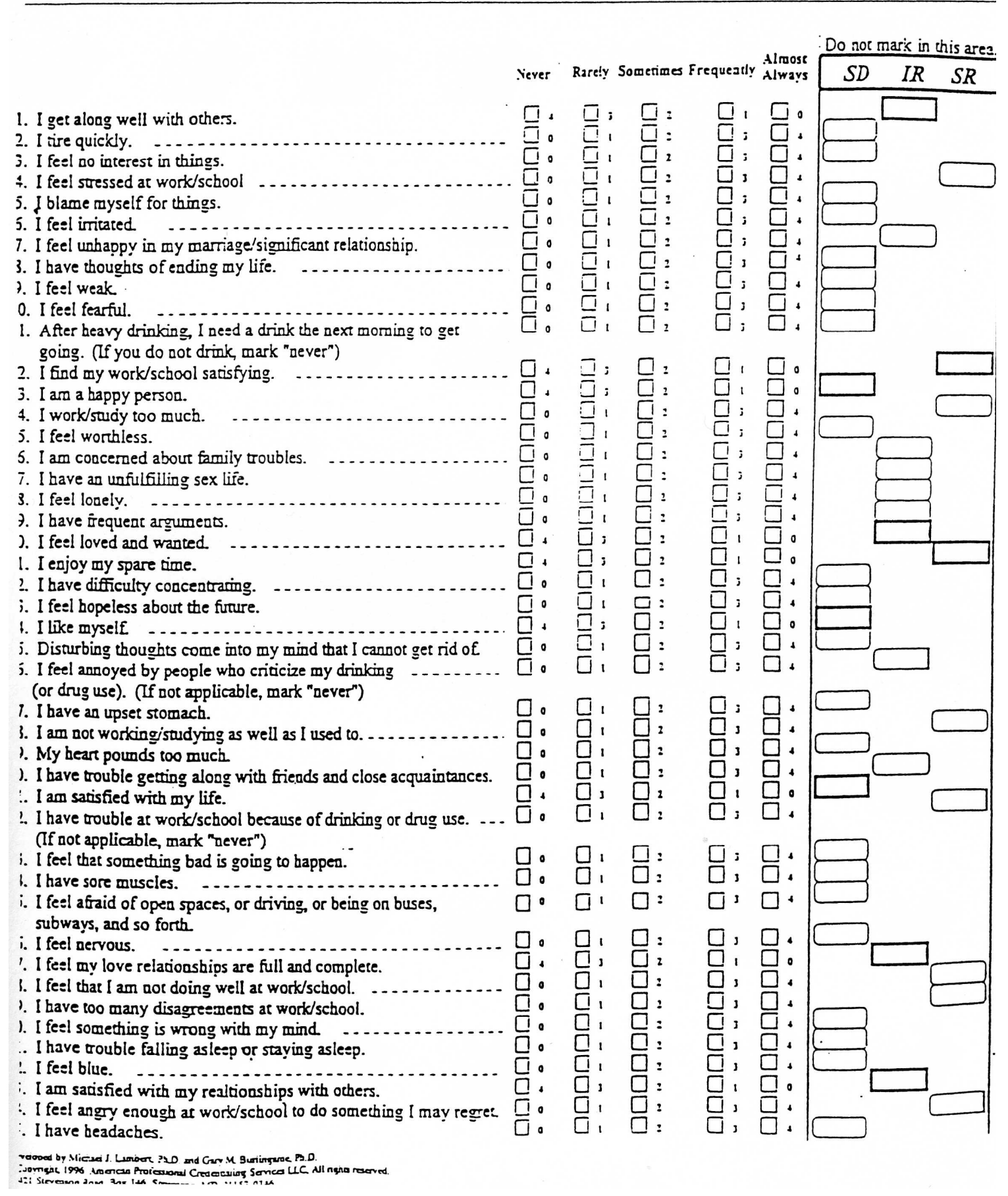


CURRICULUM VITAE

MARY LAMONT

1437 N. Fowler Ave.

Ogden, UT 84404

801-540-4529

Email: mlamont@weber.k12.ut.us

\section{Education:}

$\begin{array}{llll}2010 & \text { Ph.D. } & \begin{array}{l}\text { School/Counseling/Clinical } \\ \text { Combined Program }\end{array} & \begin{array}{l}\text { Utah State University } \\ \text { Logan, UT }\end{array} \\ & & \text { School Psychology } & \text { Utah State University } \\ & & \text { Logan, UT } \\ 1988 & \text { M.S. } & \text { Special Education } & \text { University of } \\ & & & \text { Wyoming } \\ 1995 & \text { M.A. } & & \text { Laramie, WY } \\ & & \text { Special Education } & \text { Utah State University } \\ & & & \text { Logan, UT }\end{array}$

\section{Clinical Employment}

1998-2007

2008-2010

2007-2008

APA Psychology Intern

1997-1999

Research

\section{Teaching Employment}

Research Assistant

2000-2004

School Psychologist
Weber School District Ogden, UT

Nebraska Professional Psychology Internship Consortium

Omaha, NE

Early Intervention

Institute, Logan, UT

Psychology

Utah State University

Logan, UT 
2000

1999

1996-1997

1996-1997

1988-1997

Instructor

Educational Psychology

Special Education Teacher
Utah State University

Developmental

Psychology

Logan, UT

Utah State University Logan, UT

Western Wyoming Community College Rock Springs, WY

Western Wyoming Community College Rock Springs, WY

Sweetwater School District \#1

Rock Springs, WY

\section{Research Experience}

1998

1998

1996-1997

1995
Stress, Coping and Uplifts of Adolescents with Disabilities

Emotional Abuse

Promoting Resilient Outcomes

Project

Educational Inclusion of Children with

Disabilities in the State of Wyoming
Early Intervention

Research Institute

Master's Requirement

Early Intervention

Research Institute

Master's Thesis

\section{Professional Affiliations}

American Psychological Association

National Association for School Psychologists

Utah School Psychologist Association

Utah Association for Play Therapy

Utah Association for Infant Mental Health

World Association for Infant Mental Health

Council for Exceptional Children 


\section{Licensure}

Certified School Psychologist (Utah State Office of Education)

Certified School Counselor (Utah State Office of Education)

Certified Special Education Teacher (Utah State Office of Education) 